\title{
The Drosophila sloppy paired locus encodes two proteins involved in segmentation that show homology to mammalian transcription factors
}

\author{
Ueli Grossniklaus, Rebecca Kurth Pearson, and Walter J. Gehring \\ Biozentrum, University of Basel, $\mathrm{CH}-4056$ Basel, Switzerland
}

\begin{abstract}
The sloppy paired locus is involved in the establishment of the metameric body plan of the Drosophila embryo. We have cloned the sloppy paired locus by P-element-mediated enhancer detection. The locus is composed of two genes, slp1 and slp2, that are structurally and functionally related. They belong to a novel class of putative transcription factors containing a fork head domain that has also been found in mammalian hepatocyte transcription factors. The spatial expression patterns of the two transcripts are very similar, suggesting common regulation of the two genes. We recovered additional sloppy paired alleles by remobilization of an enhancer detector transposon. Genetic analysis suggests that both genes contribute to the segmentation phenotype that has characteristics of both, pair-rule and segment polarity genes, and that they interact functionally. The two genes appear to share an enhancer element situated upstream of slp1 that acts on both the proximal slp1 promoter and the distal slp2 promoter.
\end{abstract}

[Key Words: Drosophila; fork head domain; gene complex; head development; segmentation]

Received February 10, 1992; revised version accepted April 6, 1992.

In prokaryotes, many genes having related function are organized and controlled as linked units or operons. In contrast, there are only a few examples of eukaryotic genes that are functionally related and organized as a linked unit. Several linked gene clusters have been described in Drosophila melanogaster. A genetic analysis of homeotic mutations affecting thoracic and abdominal segmentation led to the discovery of two gene complexes, the Bithorax (Lewis 1978) and the Antennapedia complex (Kaufman et al. 1980), both of which contain genes that play an important role in the establishment of the metameric body plan of Drosophila. Cloning of these complexes revealed that the constituent genes are not only functionally related but also share an important structural feature: a nucleotide sequence of $180 \mathrm{bp}$, the homeo box, which has been highly conserved, indicating an evolutionary, structural, and functional relationship (McGinnis et al. 1984; Scott and Weiner 1984).

In addition to the genetically and molecularly welldefined Antennapedia and Bithorax complexes several loci composed of only two structurally related genes have been described in Drosophila, including the serendipity locus (sry $\delta$ and $\beta$; Vincent et al. 1985), the engrailed locus [engrailed (en) and invected (inv); Poole et al. 1985, Coleman et al. 1987], the gooseberry locus Igsbproximal and gsb-distal; Baumgartner et al. 1987; Côté et al. 1987), the zerknüllt (zen) region of the Antennapedia complex (z1 and z2; Rushlow et al. 1987), and the yolk protein locus (yp1 and yp2; see Hung and Wensink 1983). The predicted proteins of each of these loci show considerable sequence homology. In addition, the genes of any particular locus are expressed in virtually identical or at least partially overlapping spatial patterns. It has been suggested that such loci originated from the duplication of an ancestral transcription unit and subsequently the genes diverged and may have acquired different functions. Little is known about the functional relationship between the genes of any of these loci owing to a lack of detailed genetic characterization. For the sry and en loci the function of only one of the genes is known (sry $\delta$ and en are embryonic lethal; Kornberg 1981; Lindsley and Zimm 1990). The gsb genes are located in a cluster that includes several genes involved in cuticular patterning (Côté et al. 1987). The only mutations described for the $g s b$ locus are deletions removing several genes of this cluster (see Côté et al. 1987); therefore, a functional discrimination between the $g s b$ genes is not yet possible. Several lines of evidence suggest that $z 1$ corresponds to zen, an embryonic lethal mutation (see Wakimoto et al. 1984), and that $z 2$ is dispensable [ $z 1$ alone can rescue zen ${ }^{-}$embryos (Rushlow et al. 1987); embryos deficient for $z 2$ are viable (Pultz et al. 1988)]. As the zen mutations used in these studies affect the expression of both genes, the phenotype of a mutation exclusively affecting $z 1$ is not known. Therefore, it is possible that either $z 1$ or $z 2$ can provide $z e n^{+}$function if one 
of the genes is removed. Mutations in the yp genes cause female sterility. This phenotype, however, seems to be a secondary effect (Bownes and Hodson 1980; Wiliams et al. 1987).

Two of these gene complexes, en and $g s b$, are involved in the subdivision of the Drosophila embryo into segments. This process is controlled by the zygotically active segmentation genes. On the basis of their cuticular phenotype in terminally differentiated embryos, the segmentation genes can be subdivided into three classes. Mutations in the gap genes result in nonperiodic deletions of several adjacent segments in homozygous mutant embryos. Pair-rule and segment polarity mutants lack pattern elements in alternate or all segments, respectively (Nüsslein-Volhard and Wieschaus 1980). The three classes of segmentation genes act in a regulatory hierarchy leading to a progressive subdivision of the embryo along its anteroposterior axis (for review, see Ingham 1988). Many of these genes are structurally related, for example, containing homeo domains (for review, see Affolter et al. 1990; Hayashi and Scott 1990) or zincfinger domains (e.g., Rosenberg et al. 1986; Tautz et al. 1987). Based on these homologies they are thought to be transcriptional regulators. However, there are also segmentation genes involved in signal transduction and cell-cell signaling (for review, see Ingham 1991).

Here we report on the molecular and genetic characterization of the pair-rule locus sloppy paired $(s l p)$ originally identified in a screen for embryonic lethal mutations affecting pattern formation (Nüsslein-Volhard et al. 1984). The locus is composed of two structurally related genes. Both slp genes contain a novel putative DNA-binding domain, the fork head domain, that is also present in the Drosophila fork head protein and in rat hepatocyte transcription factors of the HNF-3 family (Weigel and Jäckle 1990; Lai et al. 1991). Therefore, the slp proteins may be transcriptional regulators as with many other segmentation genes. A genetic analysis of newly recovered $s l p$ alleles indicates that the $s l p$ genes play a more important role in pattern formation than previously suspected and that they functionally interact in the segmentation of the embryo.

\section{Results}

Using the enhancer detector transposon $\mathrm{P}[\mathrm{lArB}$ ] (Bellen et al. 1989; Wilson et al. 1989) two transposants were recovered on the $\mathrm{CyO}$ balancer chromosome that showed a segmentally repeated $\beta$-galactosidase $(\beta$-gal $\rangle$ expression pattern reminiscent of the pair-rule and segment polarity genes (Hafen et al. 1984; Fjose et al. 1985; Kornberg et al. 1985; for review, see Akam 1987; Ingham 1988). Both insertions, P[1ArB]A208.1M2 and P[lArB]A509.1F2, hereafter referred to as 208 and 509, map to the cytological location 24D (Bellen et al. 1989) and show identical $\beta$-gal expression patterns, the only obvious difference being higher levels of $\beta$-gal expression in 509 as compared with 208 . The expression pattern as well as the cytological location of the insertions sug- gested that they were close to or at the slp locus that had been mapped to 24C-D (Nüsslein-Volhard et al. 1984).

\section{Cloning of the slp locus and mapping of transcription units}

Genomic DNA adjacent to the $3^{\prime}$ end of insertion 208 was cloned by plasmid rescue (Wilson et al. 1989) and used to probe a Drosophila genomic library (Maniatis et al. 1978). Several genomic phages spanning $28 \mathrm{~kb}$ around the insertion site were recovered. Genomic DNA adjacent to the 509 insertion was also cloned by plasmid rescue and was used to map this insertion to a $0.8-\mathrm{kb}$ EcoRI fragment $\sim 10 \mathrm{~kb}$ away from insertion 208 (Fig. 1A).

All EcoRI fragments from the $28-\mathrm{kb}$ region (Fig. 1A) were used to probe developmental Northern blots. Two nonoverlapping transcripts were detected: a $1.5-\mathrm{kb}$ transcript, which will be referred to as $\operatorname{sip} 1$, and a $2.2-\mathrm{kb}$ transcript, which will be referred to as slp2 (Fig. 1B). The slp 1 transcript is already present at $0-3 \mathrm{hr}$ of embryogenesis, whereas $\operatorname{slp} 2$ first appears at 3-6 hr. Both transcripts show maximal expression at 3-6 hr, after which levels fall off steadily until the end of embryogenesis. The transcripts are reexpressed strongly in first-instar larvae and again weakly in third-instar larvae.

\section{Generation and molecular mapping of additional slp alleles}

The CyO chromosome carrying the 208 insertion is viable over a chromosome carrying either a deficiency of this region [Df(2L)ed ${ }^{S Z 1}$; Reuter and Szidonya 1983] or an ethylmethane sulfonate (EMS)-generated slp allele (slp ${ }^{7 L 48}$; Tearle and Nüsslein-Volhard 1987), suggesting that the 208 insertion has not disrupted the slp gene. The CyO chromosome carrying insertion 509, however, is lethal over $s 1 p^{7 L 48}$ and the deficiency. Insertion 509 is allelic to $\operatorname{slp}$ as homozygous embryos display a $s 1 p$ phenotype (see Fig. 8B, below). The P[lArB] in transposant strain 509 is inserted just upstream of the $\operatorname{slp} 1$ transcript (Fig. 1A) and presumably is the cause of the slp mutation. To generate additional slp alleles a "jumpout" experiment was performed in the hope of isolating new sIp alleles from imprecise excisions of insertion 208. We recovered four jumpout chromosomes that were lethal over $\operatorname{slp}^{7 L 48}$ (see Materials and methods).

To determine whether there have been rearrangements in these four chromosomes genomic DNA isolated from the jumpout strains was subjected to Southern blot analysis using EcoRI fragments flanking the 208 insertion as probes. DNA rearrangements produce anomalous restriction fragments that cross-hybridize to probes from nonadjacent regions of the original restriction map (Fig. 1C,D). For example, the anomalous $2.5-\mathrm{kb}$ fragment detected by the $0.8-\mathrm{kb} E c o \mathrm{RI}$ probe in strain $\Delta 34 \mathrm{~B}$ (Fig. $1 \mathrm{C}$ ) also cross-hybridizes to a 2.3-kb EcoRI fragment (data not shown) that is located at a distance of $12 \mathrm{~kb}$ on the wild-type map. This strongly suggests that the imprecise excision deleted $\sim 12-\mathrm{kb}$ of genomic DNA 


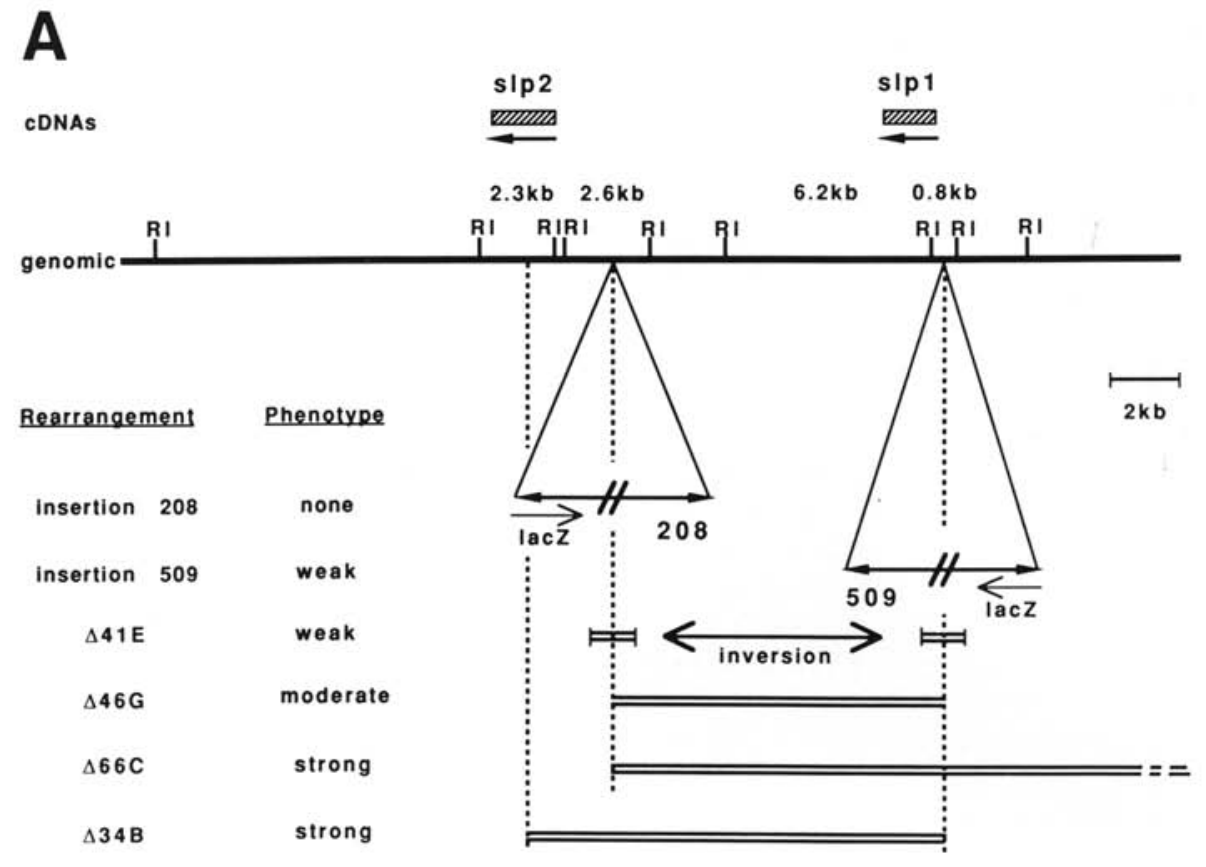

B

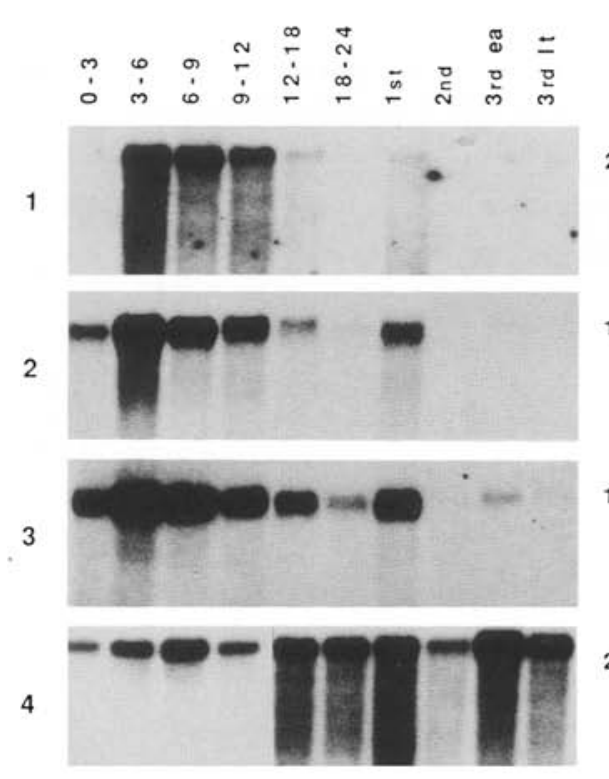

C

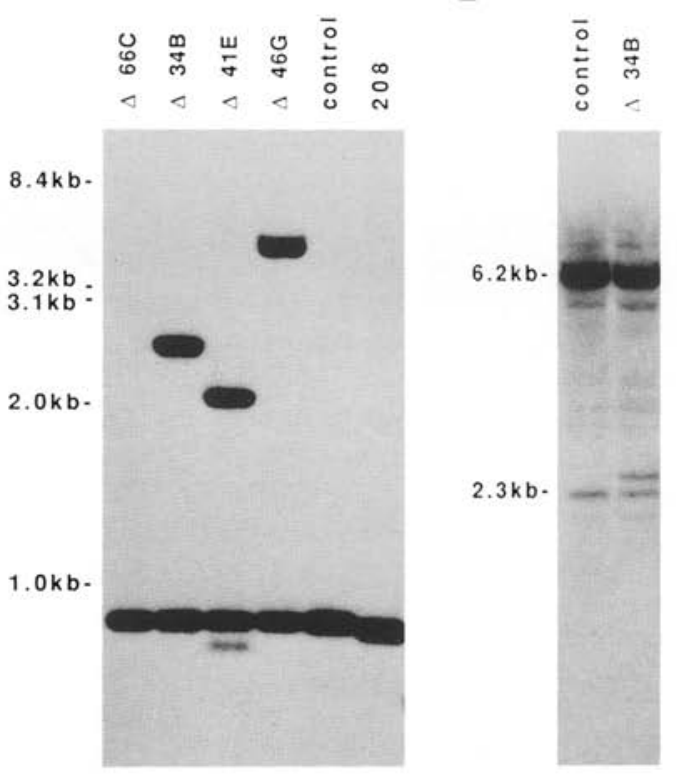

Figure 1. Isolation and molecular characterization of the $\operatorname{sip}$ locus. $(A)$ Molecular map of the genomic region containing the $\operatorname{slp}$ locus. (RI) EcoRI. Two cDNA clones, slp1 and slp2, are indicated corresponding to the two transcription units. The direction of transcription is shown by arrows. The two $\mathrm{P}[\mathrm{ArB}]$ insertions and the molecular structure of the rearrangements produced by remobilization of insertion 208 are shown beneath the genomic map. Open bars indicate the extent of genomic deletions in $\Delta 46 \mathrm{G}, \Delta 66 \mathrm{C}$, and $\Delta 34 \mathrm{~B}$. In $\Delta 4 \mathrm{lE}$ an inversion between the $\mathrm{P}$ element and the $0.8 \mathrm{~kb}$ fragment has occurred. In $\triangle 34 \mathrm{~B} \mathrm{P}[\mathrm{lArB}]$ is completely deleted, whereas in the other rearrangements parts of the enhancer detector are still present (e.g., lacZ and Bluescript sequences; for a molecular map of $\mathrm{P}[\mathrm{lArB}]$, see Wilson et al. 1989). The strength of the phenotype (see below) observed in embryos homozygous for a corresponding rearrangement is indicated. $(B)$ Developmental Northern blots. (Panels 1,2), Northern blot A probed with the 2.3-kb RI and the 6.2-kb RI fragment, respectively (see $A$ ). (Panels 3,4 ), Northern blot B probed with the 0.8 -kb RI fragment and a EFl $\alpha$ cDNA (Hovemann et al. 1988 to estimate the relative amount of poly $(\mathrm{A})^{+}$RNA loaded into each lane. Sizes of cross-hybridizing RNAs are indicated. The 2.6-kb RI fragment hybridizes very weakly to the 2.2-kb RNA (not shown). Embryonic stages are given in hours after egg deposition; first, second, third ea, and third lt correspond to RNA isolated from first-, second-, early third- and late third-instar larvae. Several RNA samples contain degradation products. $\{C, D\}$ Genomic Southern blots. DNA was isolated from mutant and control stocks and digested with RI. Fragment sizes or marker lengths are indicated. $C$ was probed with a genomic 0.8 -kb RI fragment (see $A$ ). Anomalous bands in $\Delta 34 \mathrm{~B}, \Delta 41 \mathrm{E}$, and $\Delta 46 \mathrm{G}$ indicate a rearrangement breakpoint in this fragment. The second faint anomalous band in $\Delta 41 \mathrm{E}$ suggests that this rearrangement is an inversion. $D$ was probed with a slp1 cDNA that hybridizes strongly to the 6.2-kb RI fragment but also cross-hybridizes to the 2.3 -kb RI fragment that encodes slp2. The anomalous band in $\Delta 34 \mathrm{~B}$ indicates that this deletion has a breakpoint in the 2.3-kb RI fragment. Faint bands may correspond to other genes encoding a fork head domain (see below). 
fusing the two fragments in this strain (the 19-kb P[lArB] element has also been deleted). The DNA rearrangements present in the four jumpout strains $\triangle 41 \mathrm{E}, \Delta 46 \mathrm{G}$, $\Delta 66 \mathrm{C}$, and $\Delta 34 \mathrm{~B}$ were mapped accordingly and are schematically shown in Figure 1A. Interestingly, the right breakpoints of three of the four independent jumpouts, as well as insertion 509, all map within the $0.8-\mathrm{kb} E c \mathrm{RI}$ fragment (Fig. 1C): The insertion site of strain 509 and the right breakpoint of inversion $\triangle 41 \mathrm{E}$ occur at the same base pair, whereas the right breakpoint of deletion $\Delta 46 \mathrm{G}$ is located $70 \mathrm{bp}$ farther upstream (Fig. 2A).

\section{Sequence determination and predicted slp1 and slp2 proteins}

The complete nucleotide sequence of a composite slp1 cDNA and a slp2 cDNA are shown in Figure 2. Sequencing of genomic DNA corresponding to the two transcription units indicated that neither slp1 nor slp2 contain introns. Comparison of the length of the cDNA obtained by sequencing (1486 bp for slp1; $1908 \mathrm{bp}$ for slp2) with the size of the mRNA detected by Northern blot analysis (1.5 kb for slp1; $2.2 \mathrm{~kb}$ for slp2) suggests that all of the slp1 and nearly all of the slp2 sequences corresponding to the transcripts were recovered (for details, see Materials and methods). The longest open reading frames (ORFs) of the slp1 and slp2 cDNAs extend over $966 \mathrm{bp}$ and $1335 \mathrm{bp}$, respectively. The first methionine codons at nucleotide residue 268 and 332 are in the context of $5^{\prime}$-AAAAATG3 ' and 5'-AAATATG-3', respectively, fitting the Drosophila translational start site consensus sequence $5^{\prime}-\mathrm{C} /$ AAAA/CATG-3' (Cavener 1987). If translation is initiated at these methionines the ORFs would encode a slp 1 protein of 322 and a slp2 protein of 445 amino acids.

The two predicted proteins have several interesting features. They share a large region that is highly conserved (region I in Fig. 3A): slp1 and slp2 share 81 of 107 amino acid residues $(76 \%)$. This region, termed the fork head domain (Weigel and Jäckle 1990), is also present in the predicted Drosophila fork head protein $(f k h$; Weigel et al. 1989) and in three transcription factors enriched in rat liver (HNF-3 $\alpha$, HNF-3 $\beta$, and HNF-3 $\gamma$, Lai et al. 1990, 1991). These four proteins show a remarkable homology spanning 110 amino acids. Lai et al. (1990) demonstrated that the region between amino acids 124 and 288 in HNF-3 $\alpha$, a sequence including the fork head domain, is required for DNA binding.

The fork head domains of slp1 and slp2 are more closely related to each other than to the remaining members of the family, especially in the carboxy-terminal part (Fig. 3B). If one considers only the last 100 amino acids of the domain, slp2 is $75 \%$ identical to slp1 but only $51 \%$ identical to $f k h$, the closest relative of the other proteins that among each other show degrees of homology on the order of $90 \%$. The first 10 amino acid residues of the domain are only conserved among $f k h$ and the HNF-3 factors. The slp proteins do not show any homology to each other or the other proteins in this most amino-terminal part of the fork head domain, but there is a more extensive homology found only between slp1 and slp2 at its carboxy-terminal end. Lai et al. (1991) also described two short carboxy-terminal domains, regions II (region C in Weigel and Jäckle 1990) and III that are conserved among the HNF- 3 factors and $f k h$. These two regions are present in the slp proteins as well, but at different locations (Fig. 3B,C).

\section{Spatial and temporal distribution of the slp transcripts}

We analyzed the spatial and temporal expression of $\operatorname{slp} 1$ and slp2 during embryogenesis by whole-mount in situ hybridization with digoxigenin-labeled probes (Tautz and Pfefle 1989|. As the two slp sequences show considerable homology, we designed specific probes derived from the 3' end of the corresponding cDNAs for each of the slp genes (for details, see Materials and methods). Both genes are expressed in similar patterns. There are temporal differences in their expression, however, as well as spatial ones during early embryogenesis. The distribution of slp mRNA closely resembles the expression of lac $Z$ mRNA and $\beta$-gal in the original enhancer detector strains 208 and 509 (data not shown).

The slp1 transcript is first detected in a gap gene-like expression pattern during syncytial blastoderm (stage 4 of Campos-Ortega and Hartenstein 1985) at about nuclear division 10 in a region ranging from $-70 \%$ egg length ( $\mathrm{EL} ; 0 \%$ being the posterior pole) to the anterior tip of the embryo (not shown). Although expression in the head region increases, a repression of $\operatorname{slp} 1$ expression in the most anterior region is observed (Fig. 4A). Toward the end of syncytial blastoderm slp 1 is expressed in a broad circumferential ring in the anterior region of the embryo. Dorsally, the ring covers $\sim 9-10$ nuclei at $\sim 81 \%$ EL to $\sim 70 \% \mathrm{EL}$, and ventrally $\sim 15$ nuclei at $\sim 87 \%$ EL to $\sim 71 \%$ EL (Fig. 4B). Subsequently, the anterior half of the head ring is ventrally repressed (Fig. 4C,D) such that now only one-half of the head ring is circumferential. At the beginning of cellularization, when the first cell membranes become visible (stage 5 of Campos-Ortega and Hartenstein 1985), this pattern evolves into a circumferential stripe that is separated from an anterior cap as a result of progressive loss of transcripts in intervening cells resulting in a gap lacking $\operatorname{sip} 1$ transcripts $(\sim 2-3$ cells; Fig. 4E). This stripe has a special shape curving posteriorly on the ventral side of the embryo (Fig. 4J,K). Coinciding with the splitting of head expression into an anterior cap and a circumferential stripe the first signs of the metameric pattern appear: six evenly spaced stripes each approximately two cells wide appear posterior to the head stripe (Fig. 4E-I). First, the anterior-most of the six stripes evolves; then more posterior ones follow. The very first expression of each stripe is detected in the ventrolateral region of the embryo, rapidly extending more ventrally and somewhat slower more dorsally. The stripes do not extend all around the circumference of the embryo but remain unconnected on the dorsal side (Fig. 4I). The stripe derived from the early head expression is also repressed dorsally and later on even the head cap shows this dorsal repression yielding two broad lateral regions of expression in the head (not shown). The pri- 
A

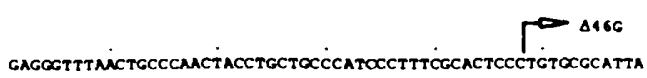
SO9. $\Delta 41 E$ GСтACCCGTCTCTTTCCECCTCTCCGCTCTCTTCGTCTASACTTCGTTCGACOGACCGC

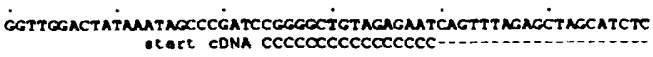

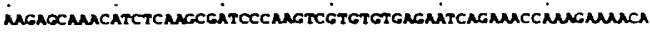

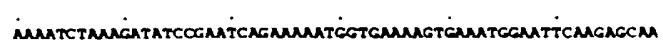

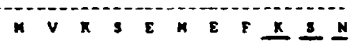

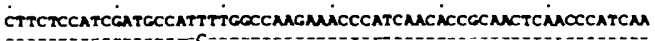

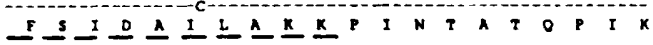

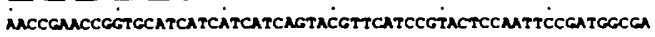
T E P B I I Q Y V P Y B N S O G E

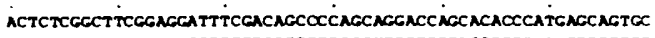
I S A S E D F D S P S R T S T P A S S A CGCCGAGAGTCTATCGTCGCAMMCANTCACMACCTCGACGTCGAGTTCGACGATGAGCT A E S L S S O N N D K L D V E F D D E L GGNGGATCNGCTGGACGAGGACCACGAGAGCGGGCATGGCCMATCCCAGCMUGMUCAGM E D O L D E D O E S E D G N P S KK는

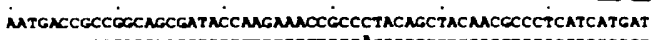

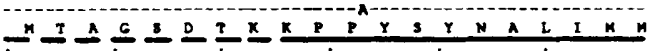
GGCCATCCAGGATAGTCCCGACCAGCGGTTGACTTTGMATOGCATCTATCACTATCTGAT A I O D S P E Q R L T L NG I Y Q Y L I

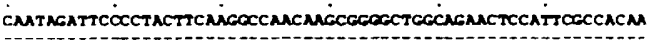
N R F P Y F K A N X R G M Q N

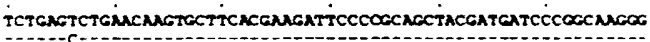
\begin{tabular}{l}
$L_{2}$ \\
\hline
\end{tabular} CMACTACTCGATCCTGCACCCCTCСCCCCACGACOTATTCATTCGCGAGACCACCGGCM N Y N I L D P 3 A E E V T I G E T T G K

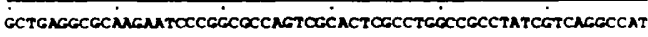

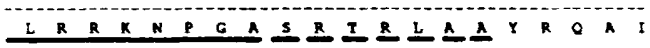
АTTCTCGCCGRTGATGOCTGCTTCACCCTACGGACTCCAOCTCCCAGCTATCCATACCC F S P M A A S P Y GA PA P 8 Y G Y P

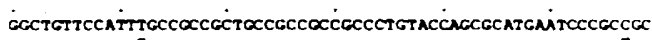
$A V P F A A A A A A A L Y Q R A N P A A$ СтAтCACGCTOCCTATCAGCAGATGCACTACCAGCACGCTOCCCACOCCCACCATCATCA

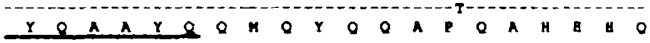
GGCGOCCCATOCCGCCCAGATGCAGCOCCTATCCACCACAMTTGAACOCCGGAGTTGTTCCA A P B P A O H O G Y P P O L N A E L F O GCGCATGCAGTTCTTTळCCNAGTTCCCATCCACCTMUTCTTCGCCACTCGGCOCAGMACC R M O F F G K E P S S

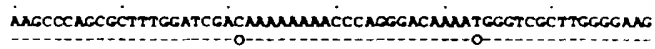

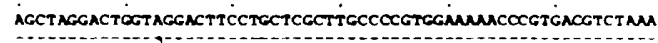
TGCTœCATTTACCAMATTCCTTTCGTCATCATCGCATTGACCGCTTOCCTTCTTCACCOC

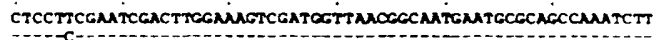

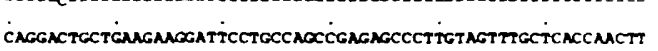

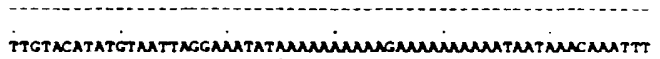

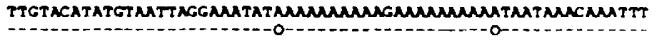

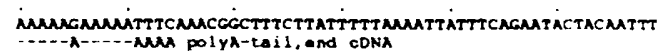

B. 60

220

180

240

300

360

10

420

30

180

50

540

600

90

660

210

720

130

780

150

840

170

900

190

960

210

1020

230

2080

250

1140

270

1200

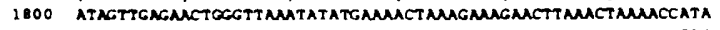

1860 TTOCGTTGACCGGATTTAATAMAGGCCTTTGCAGAGTTTGTGMUATATCСGMUСTATTA

1920 MUAMGMULTACCATCCCTACTCTTTCGTCTAMATGAGMATATAMTTTATAATEGMAC

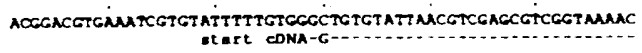
TGMCGTMAGCGAGAGMACTGMCGMATGNOCCCCMUTTTEMUACCTACTGACTTTGA

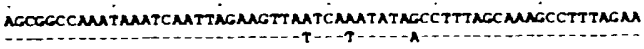

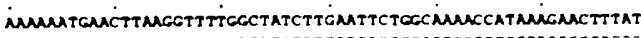

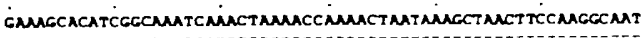

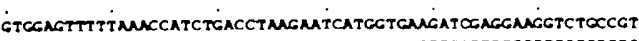
K V K I E 2 G L ?

CCAGCGAGATTAGOSCTCACAOTCTCCACTTTCAGCAOCATCAOCACCCACTCCCCOCCCA S 5 E I S A B S L G F O G B A B P L P P

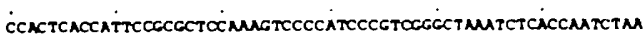

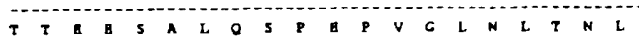

TGMMATOCCCACGACGCCACATCTGMACTCCAGCTTTTCCATTMATTCCCATTCTACCCG

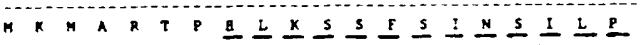
AGACTGTOCAGCATCACGACGAGGATGAGGUGGAGGATGTCGAGMGGMUTCACCAGCGA E I V E G D E D E E E D V E K K S P A

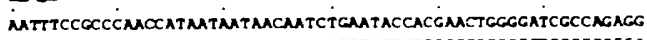
K I P P N I N N N N L N T T N N G S P E ATCATCAOSCGGMULCGATCCCGMTCGGATCTCGATCTGACCTCCATGTCACCOSCTC D E A E S D P E S D L D V T S M S P A

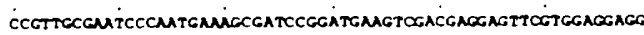
P V A N P E S D P D E V O E E E V E E

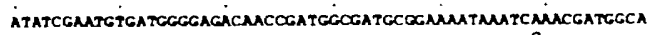
D I E C D G E T T D G O A E N K S M D G

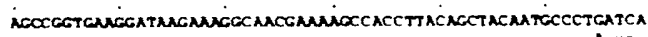

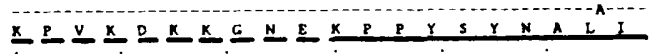
TGATGGCCATTCGTCAGASTICCGAGANGCGTCTAACOCTGMATGGCATCTACGAGTACA KA A I R S S S E K R L T L N G I Y E Y

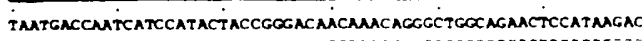
1
1 ATMATTTGACCCTCMUTMGTGTTTCGTCAMGOTGCCMACACACTATGATGATCCTGGCA

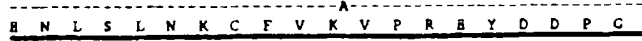
AGCOCMACTACTGGATCTTOGATCCCTCGGCOOMGACOTATTCATTGGOGGATCGACGC K G N Y N M L D P S A E D V F I G G S T GGMACCTCACGAGMGMCCCACACCOCCCTCTCGCTCOCGACTCECCCCCTTCMAGAGAT

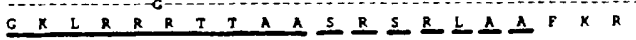
CGCTGATACGACCCATGTTCCCGGGACTGGCTGCCTATCCGCAGTTTCCACAMTTTCTTA 5 L I G P M F P G L A A Y P O F G O F L CCTATCCTCCGACOGCGCCTASCTTCCTGCCCAGCATGTATCACCGTTATAATCCCTTTG T Y P P T A P S L L A S M Y QRY Y P P F CCOCGMANGGTGGACCAGGACATCCGGGCTTOCCACCOCGCTT ФGGGATTACCCCOGACC \begin{tabular}{l}
$A$ \\
\hline
\end{tabular}$\quad$ G G G P G A P G L P P G L R D Y P ACCGGGaCCtCMAOGACCGCCAGGACCACCACCACCGOCCTtTCGTCGCACCACCCCACGaG B R D L K D R O D B A H R P S S H B P R CAGTGACCTCTACCAGCGATTGCAGTACCAMCACCTGTTCCATCMCATC人AGCACCCGC A V S S T S D C S T N S C C I N M O O P CGCTCTCOCGGCTCATCAMCGCCMACTCTCGGTGGCGCOCAGCATCGGCGOCCTTCACAMCC

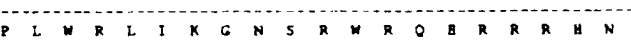

ACOSCCCACTCATCACCACCCACACCTGGCCOTGGGTCAGGCGCCCCTTTCGCCTCGCGg A R P L I T T G T N R W V R R P F R L A

CGATTCCOCGGGAOCCTCGCCACAGCCTCTTCACMUCCCCGTCACCGTAGTCTCCCGCAM

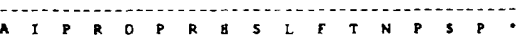

IAOCTGUCATTCTGCCGASGMGATCGGMAGATTCTTTCGCTTGACGAOCAGCATATGT MGCTCATMGTATTCACTCTACATAGATAT AOCCGCGACTGAGCOGCTAGACGCTTGTM MATMGMUATACCATCCCTAC

Figure 2. (See facing page for legend.) 
A
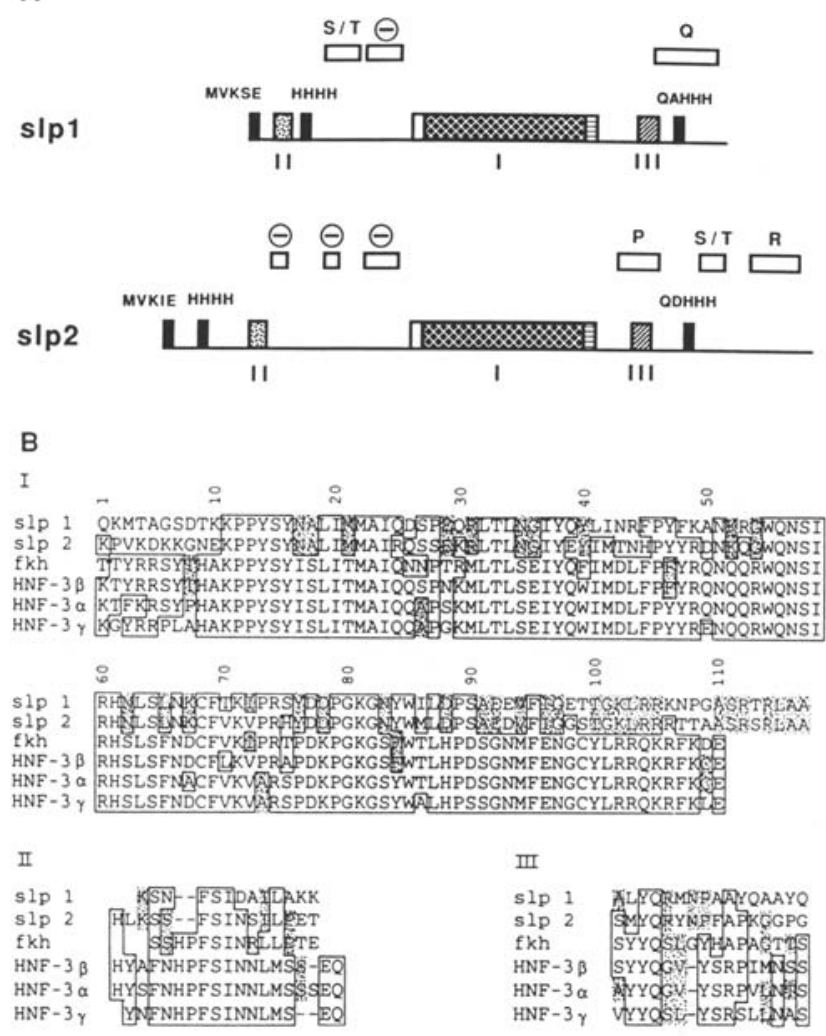

C

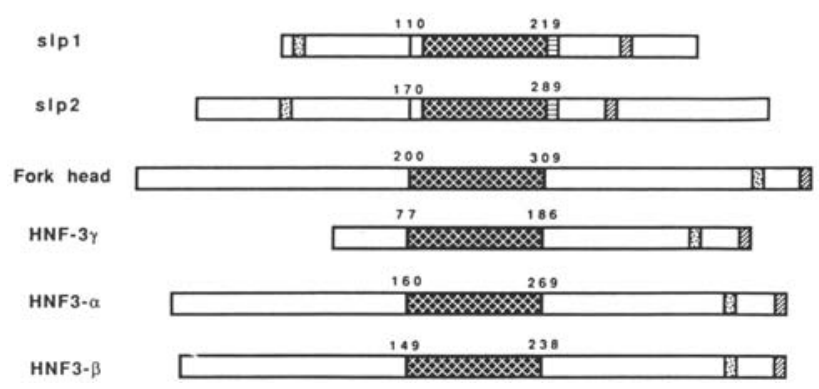

mary stripes have a width of about two cells and between them there are approximately six cells devoid of transcripts suggesting a two-segment periodicity of the pattern as observed for other pair-rule genes. All stripes are of similar intensity with the exception of the third of the
Figure 3. Structural features of the predicted slp proteins. $\{A\}$ Diagram of the predicted slpl and slp2 proteins. Conserved sequences are shown as boxes with different shadings. Regions enriched for certain amino acids are indicated above the proteins. Acidic regions are composed of $>60 \%$ acidic residues, $\mathrm{S} / \mathrm{T}$ stretches consist of $\sim 50 \%$ serine and threonine, regions enriched for glutamine $(\mathrm{Q})$, proline $\langle\mathrm{P}\}$, and arginine $(\mathrm{R})$ contain $\sim 30 \%$ of these residues. $|B|$ Homology of amino acid sequence among slp1, slp2, fork head, and the rat transcription factors of the HNF-3 family. Sequence comparison of the fork head domain (I) and two short regions of homology (II and III). Boxed areas: three or more members share the same amino acid. Stippled areas: sequence identity between only two of the proteins. $(C)$ Diagram of the proteins showing the location of the homologous regions I, II, and III.

six newly evolving stripes that often appears a bit narrower (due to stretches where it is only one cell wide) and that does not extend initially as far dorsally as the others (Fig 4H,I).

Toward the end of cellular blastoderm, when the pri-

Figure 2. Nucleotide sequence of $\operatorname{sip} 1$ and $\operatorname{sip} 2$. The sequences of genomic regions covering the $\operatorname{slp} 1$ and $\operatorname{slp} 2$ transcription units are presented. The cDNA sequences are given below the genomic sequence; a hyphen indicates identity, 0 indicates that this base is deleted in the cDNA. Frameshift mutations occurred in the leader and trailer sequences. Base substitutions present in the coding region of both genes are generally silent. Two nonsilent substitutions for slp2 and five for slp1 could be detected in the carboxyterminal regions of the coding sequence. Differences between genomic and cDNA sequences may be the result of polymorphisms (libraries derived from flies of different genetic background) or of cDNA synthesis artifacts. The bold line highlights the part of the fork head domain (region I) that is conserved among all six members of the fork head domain family. Parts of region I that are only conserved among some of the members are underlined by a broken bold line. Regions II and III are underlined by thin broken or solid lines, respectively. The predicted amino acid sequence is shown beneath the middle base of each codon. $(A)$ Nucleotide sequence of slp1. The arrows indicate the breakpoints of the $\Delta 46 \mathrm{G}$ deletion, the 509 insertion, and the $\Delta 41 \mathrm{E}$ inversion. The polyadenylation signal $\mathrm{A}_{2} \mathrm{TA}_{3}$ (Proudfoot and Brownlee 1976) is at position 1607. Two nucleotide substitutions in the cDNA are not silent: $246 \mathrm{P} \rightarrow \mathrm{S}, 303$ $\mathrm{P} \rightarrow \mathrm{Q}$. $(B)$ Nucleotide sequence of slp2. There is a 2-bp insertion $(\mathrm{CA})$ in the cDNA at position 149 that is not indicated. Five nucleotide substitutions in the cDNA are not silent: $362 \mathrm{R} \rightarrow \mathrm{P}, 378 \mathrm{~S} \rightarrow \mathrm{N}, 387 \mathrm{Q} \rightarrow \mathrm{R}, 410 \mathrm{H} \rightarrow \mathrm{Q}, 416 \mathrm{~T} \rightarrow \mathrm{I}$. 
mary stripes are fully established, secondary stripes appear in alternate segments (Fig. 4J-M). As noted for the primary stripes, the anterior-most stripe appears first and then more posterior ones follow (Fig. 4J). The first accu- mulation is detected on the lateral side of the embryo and the stripes then extend rapidly dorsally and ventrally (Fig. 4K). On the dorsal side they remain unconnected (Fig. 4L). As the secondary stripes appear, the anterior
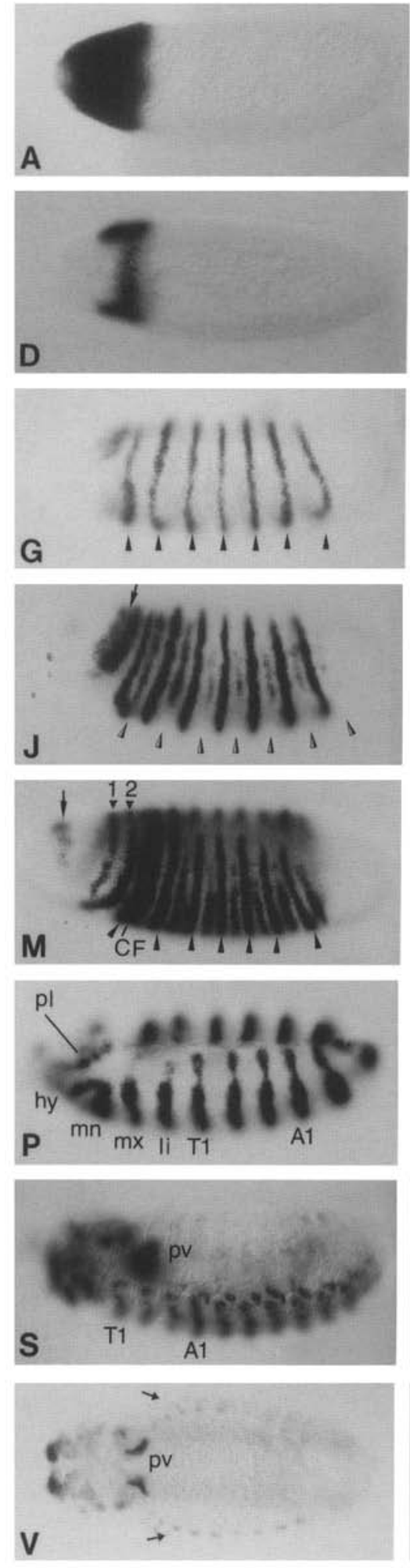
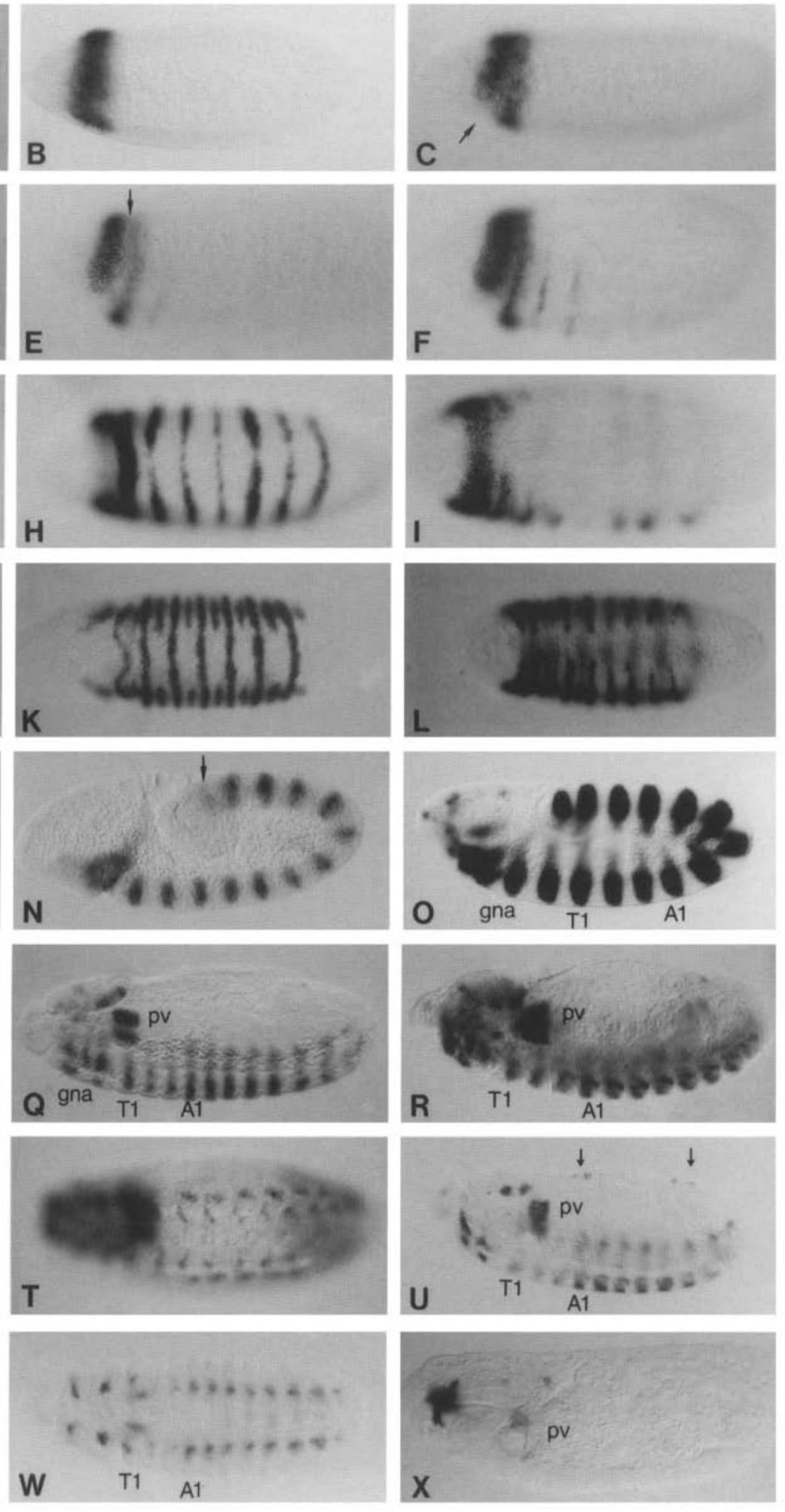

Figure 4. (See facing page for legend.) 
head cap is split into two narrower lateral patches by a loss of transcripts in an approximately two-cell wide region in the middle of the original cap (Fig. 4J,M). In addition, a new domain of expression can be detected more anteriorly in the head (Fig. $4 \mathrm{M}$ ). By the time of early gastrulation (stage 6 of Campos-Ortego and Hartenstein 1985) the secondary stripes are well established but are somewhat less intense and do not reach as far dorsal as the primary ones. Primary and secondary stripes are approximately two cells wide and are separated by two to three cells that are free of slp1 transcripts. During germband extension the width of the ectodermal stripes broadens to four or five cells and an additional stripe appears at the tip of the extending germ band (Fig. $4 \mathrm{~N}$ ). Segmentally repeated lateral cell clusters that are connected to the ventral stripes by thin stalks now also express slp1 (Fig. 4P).

The expression pattern in the head becomes very complex during germ band extension. As a result of morphogenetic cell movements in the procephalon during gastrulation some of the slp1-expressing cells derived from the early head expression have changed their original dorsoventral orientation. They now occupy a more anteroposterior orientation in the lateral procephalon (Fig. $40, \mathrm{P})$. Three large regions of slp1 expression can be distinguished: one is an elongated patch of cells in the lateral procephalon that extends toward the stomodeal opening. The other two are stripe-like patches in the hypopharyngeal and mandibular segment primordia (Fig. $4 \mathrm{P})$. In addition, slp1 mRNA can be detected in several small patches of cells in the dorsal region of the procephalic lobe and the clypeolabrum (Fig. 4O). During stage 13 the head expression becomes stronger and more extensive (Fig. 4R,S). Subsequently, most of this expression will disappear, although some faint diffuse straining in the head can be detected until the end of embryogenesis. Patches of cells in the gnathal lobes and the clypeolabrum express slp1 at high levels during head involution.
When the germ band starts to retract the metamerically reiterated pattern begins to fade and eventually disappears (Fig. 4Q-T). A loss of slp1 transcript is first observed in the stalk regions such that the lateral clusters are no longer connected to the ventral stripes (not shown). After completion of germ band shortening new slp1 expression can be detected in epidermal cells forming ventrolateral oblong cell clusters (Fig. 4R-T,W). At dorsal closure the transcript accumulates in cells at the border of the dorsal epidermis that grows dorsally over the aminoserosa to fuse at the midline (Fig. 4U,V) and, albeit fainter, in laterally adjacent regions (not shown). Once dorsal closure is completed the staining in these dorsal as well as in the ventrolateral clusters disappears.

In the proventriculus $\operatorname{sip} 1 \mathrm{mRNA}$ is first detectable during germ band shortening (Fig. 4Q). This staining can be followed throughout the rest of embryogenesis and is still present in fully developed embryos, although at a much lower level (Fig. 4X). Other internal tissues expressing $\operatorname{sip} 1$ include the ventral nerve cord that stains faintly in every segment after germ-band retraction (Fig. $4 \mathrm{~T}$ ) and a large cell cluster in the cephalic region of late embryos (Fig. 4X).

The expression pattern of $\operatorname{slp} 2$ is established by the same sequential steps and is very similar to the one described for slp1. There are, however, temporal differences in the expression of the two genes (Fig. 5A-F): slp1 expression can already be detected at the beginning of syncytial blastoderm (Fig. 5A), whereas slp2 expression starts later, just before the cell membranes form (Fig. 5E). Also, the secondary stripes of $\operatorname{slp} 1$ are fully established when gastrulation begins (Fig. 5C), whereas the secondary stripes of $\operatorname{slp} 2$ have barely started to evolve (Fig. $5 \mathrm{~F}$ ). A temporal difference in the expression of the two genes has also been noted on developmental Northern blots (see Fig. 1B).

In addition to the temporal lag of expression of slp2 in comparison with $\operatorname{sip} 1$ there are minor spatial differences:

Figure 4. Spatial expression of $\operatorname{slp} 1$ during embryogenesis. Whole-mount in situ hybridizations were performed with a slp1-specific digoxigenin-labeled probe. In all figures embryos are oriented with their anterior pole to the left. Dorsal is uppermost except where stated otherwise. In all figures Tl-3 and Al-8 indicate thoracic and abdominal segments, respectively. Developmental stages for all figures are those of Campos-Ortega and Hartenstein (1985). See text for a detailed description of the expression pattern. (A) Embryo at syncytial blastoderm (stage 4, nuclear division cycle 12 or 13). (B) Embryo at end of stage 4 . $(C, D)$ Lateral and ventral view of an embryo at cellular blastoderm (stage 5). Note ventral repression in anterior half of head ring (arrow). $\{E$ ) Stage 5 embryo. Note loss of transcripts (arrow) separating the expression domain into an anterior cap and a posterior stripe. ( $F$ ) Stage 5 embryo. The first signs of the metameric pattern appear. $(G-I)$ Lateral, ventral, and dorsal view of a blastoderm embryo where the six primary stripes are fully established. The seven-stripe pattern (filled triangles in $G$ ) has a two-segment periodicity. (J-L) Lateral, ventral, and dorsal view of an embryo during late cellular blastoderm. The secondary stripes (half-filled triangles in $J$ ) evolve. The head cap starts to become separated into two stripes (arrow in $/)$. (M) Embryo undergoing early gastrulation (stage 6). Filled triangles indicate primary stripes. The head cap has become well separated into two stripes in the procephalon $(1,2)$ and new expression domains in the head region can be detected (arrow; $\mathrm{CF}$, cephalic furrow). (N) Embryo at the end of the rapid phase of germ band elongation (stage 8). This embryo is very faintly stained and, therefore, the head expression is not visible. The last stripe is added to the metamerically reiterated expression pattern (arrow). $(O, P)$ Two different focal planes of an embryo toward the end of germ band extension (stage 10). Note the complex expression in the procephalon and the gnathal segments (gna). Stripe-like expression can be detected in the hypopharyngeal (hy), mandibular (mn), maxillary (mx), and labial (li) segment, the procephalic lobe (pl) and the clypeolabrum. (Q) Stage 13 embryo (pv, proventriculus). $(R, S)$ Two focal planes of a stage 14 embryo. Note that the thoracic segments show lower expression levels than the abdominal ones. $(T)$ Ventral view of a stage 14 embryo. The ventral nerve cord expresses slp1 in very faint segmental stripes with the highest levels of expression at the lateral edges. Expression in the ventrolateral cell clusters flanking the ventral nerve cord can be detected and is visible until stage $15(W)$. $(U-W)$ Lateral, dorsal, and ventral view of a stage 15 embryo. Cell clusters at the dorsal edge of the epidermis express slp1 (arrows). (X) Stage 16/17 embryo. 
As $s 1 p 2$ is only expressed at the very end of stage 4 , no gap gene-like expression occupying the complete anterior region of the blastoderm can be observed. Rather, slp2 mRNA first accumulates in a faint circumferential ring in the anterior region of the blastoderm. While cellularization is completed more mRNA accumulates and the ring broadens to a width of, on average, 8 cells dorsally ranging from $70-80 \% \mathrm{EL}$ and to $\sim 13$ cells ventrally from $71-85 \%$ EL. In comparison to the slp1 head expression the slp2 ring is one to two cells narrower. The posterior border of the $s l p 2$ ring coincides with the one observed for slp1. Double in situ hybridization experiments using two specific probes for slp1 and slp2 (Fig. 5G-I) showed that transcripts of both genes are present in the same blastoderm cells. A similar experiment with a slp1 cDNA and lacZ DNA as probes demonstrated that the epidermal slp1 and lac $Z$ stripes of line 509 coincide (data not shown). Thus, at least in early stages of embryogenesis, the $1 a c Z$ reporter gene reflects the expression of the slp genes with high accuracy.

\section{Relationship between slp and other segmentation gene patterns}

slp is expressed in a periodically repeated pattern, initially with a two- and later with a one-segment periodicity. To determine the relative position of the slp stripes at blastoderm with respect to other segmentation gene transcripts we performed double in situ hybridizations using slp and engrailed (en) probes (Fig. 5J-L). en demarcates the anterior compartment of each parasegment (DiNardo et al. 1985). During early gastrulation slp and en stripes are each approximately two cells wide (Fig. 5J,K). When we use combined probes the signal occupies about four cells indicating that $s l p$ is expressed adjacent to en
(Fig. 5L). To determine the relative order of slp and en we performed double in situ hybridizations using slp and fushi tarazu (ftz) probes (Fig. 5M-R). ftz is expressed in the even-numbered parasegments and initially spans three to four cells (Fig. 5N). The anterior border of $f t z$ expression delimits the anterior boundary of these parasegments (Lawrence et al. 1987). Using combined probes the signal occupies about four cells corresponding to the width of one parasegment (Fig. 5O), indicating that slp and $f t z$ are expressed in the same parasegment. Stripes 1 and 2 in Figure 50 are about six cells broad due to $s I p$ expression just anterior to the $f t z$ domain. There, the secondary $s l p$ stripes evolve first. Double labeling using antibodies directed against $\beta$-gal and $f t z$ (Fig. 5S-U) or even-skipped (eve) on transposant embryos (Fig.5V-X) was also performed. $f t z$ and eve mark even- and oddnumbered parasegments, respectively (Lawrence et al. 1987). The interpretation of our results is shown in Figure 6. In short, slp is expressed in the posterior half of each parasegment just anterior to the parasegmental boundary. Primary stripes accumulate in the even-numbered, secondary stripes in the odd-numbered parasegments.

\section{slp expression in slp mutants}

To analyze how the expression of the two slp genes is affected in EMS and newly recovered jumpout alleles we performed in situ hybridizations with specific probes on slp mutant embryos. The results are summarized in Table 1 and selected embryos showing abnormal expression of one of the transcripts are shown in Figure 7.

The two original EMS-induced slp mutations we tested $\mid s l p^{7 L 48}$ and $s l p^{I I M 105}$, hereafter referred to as $7 L 48$ and IIM105; Nüsslein-Volhard et al. 1984; Tearle and

Figure 5. Comparison of $\operatorname{slp} 1$ and $\operatorname{sip} 2$ expression and their relationship to other segmentation gene expression patterns. Wholemount in situ hybridizations were performed with individual and combined digoxigenin-labeled probes $(A-R)$. Antibody double labelings are shown in $S-X$. Probes used are given in the lower right corner. (comb) Combined probes. Antibodies are indicated by an asterisk $\left({ }^{*}\right) .(A-C)$ Development of $\operatorname{slp} 1$ expression during early embryogenesis as detected by a slp1-specific probe. $(A)$ Early stage 4 , $(B)$ late stage $4,(C)$ late stage $5 .(D-F)$ Development of $s l p 2$ expression during early embryogenesis as detected by a slp2-specific probe. $(D)$ Mid-stage 4, $(E)$ late stage 4, $(F)$ early stage 6. (G-I) Double in situ hybrization to stage 5 embryos with slp1-and slp2-specific probes. In all three embryos shown the stripes are about two cells wide indicating that the $\operatorname{sip} 1$ and $\operatorname{slp} 2$ signals completely overlap. $(J-L)$ Double in situ hybrization to stage 6 embryos with slp 1 cDNA and en probes. $(M-O)$ Double in situ hybridization to stage 5 embryos with $\operatorname{sip} 1 \mathrm{cDNA}$ and $f t z$ probes. $(P-R)$ Double in situ hybridization to stage 6 embryos with $\operatorname{sip} 1 \mathrm{cDNA}$ and $f t z$ probes. $(Q)$ By early gastrulation the epidermal $\mathrm{ftz}$ stripes have narrowed to a width of one to two cells. $(R)$ The pattern obtained with combined probes consists of a repeated unit composed of two stripes: the anterior stripe is approximately three cells wide and, therefore, is made up of $s l p$ - and $f t z$-expressing cells, whereas the posterior one is only about two cells wide and corresponds to a slp stripe. These two stripes are separated by approximately two cells that are free of signal. Each double stripe unit is separated from the adjacent one by about three cells. $(S-U)$ Embryos of transposant 509 were stained with anti- $\beta$-gal (brown) and anti-ftz (blue) antibodies. Although lacZ mRNA is expressed in the same cells as $\operatorname{sip,~the~mRNA~distribution~of~} \operatorname{slp} 1$ at blastoderm is only reflected by the protein during early gastrulation (7 stripes) and the rapid phase of germ band elongation (14 stripes). ( $S$ ) $\mathrm{ftz}$ designates the even-numbered parasegments. At blastoderm $\beta$-gal is expressed in the anterior part of the embryo. $\{T\rangle$ During gastrulation the primary $\beta$-gal stripes are well established and lie posterior to the $f t z$ stripes that have already narrowed. $(U)$ At the end of stage 8 the secondary $\beta$-gal stripes have appeared anterior to the $f t z$ stripes. $(V-X)$ Embryos of transposant 509 were stained with anti- $\beta$-gal (brown) and anti-eve (blue) antibodies. (V) eve designates the odd-numbered parasegments so that the stripes are shifted more anteriorly by one parasegment in comparison to $f t z$. $(W)$ The primary $\beta$-gal stripes lie just anterior to the eve stripes. $(X)$ By the end of stage 8 secondary $\beta$-gal stripes evolve posterior to the eve stripes. A few dark staining cells (possibly due to overlapping $\beta$-gal and eve expression domains) can be seen (half-filled triangles in $W$ and $X)$. This overlap is not consistently found in a continuous cell row and may reflect an overlap due to a certain fuzziness of the stripes. 
Nüsslein-Volhard 1987) and insertion 208 show normal expression of both slp genes. In embryos homozygous for the insertional mutant 509 and the inversion $\triangle 41 \mathrm{E}$ (see also Fig. 1A) both $\operatorname{slp}$ genes are expressed. Whereas slp2 expression is normal, slp1 is expressed at a reduced level in fewer cells than in wild-type embryos (Fig. $7 \mathrm{~B}, \mathrm{C}$ ). In

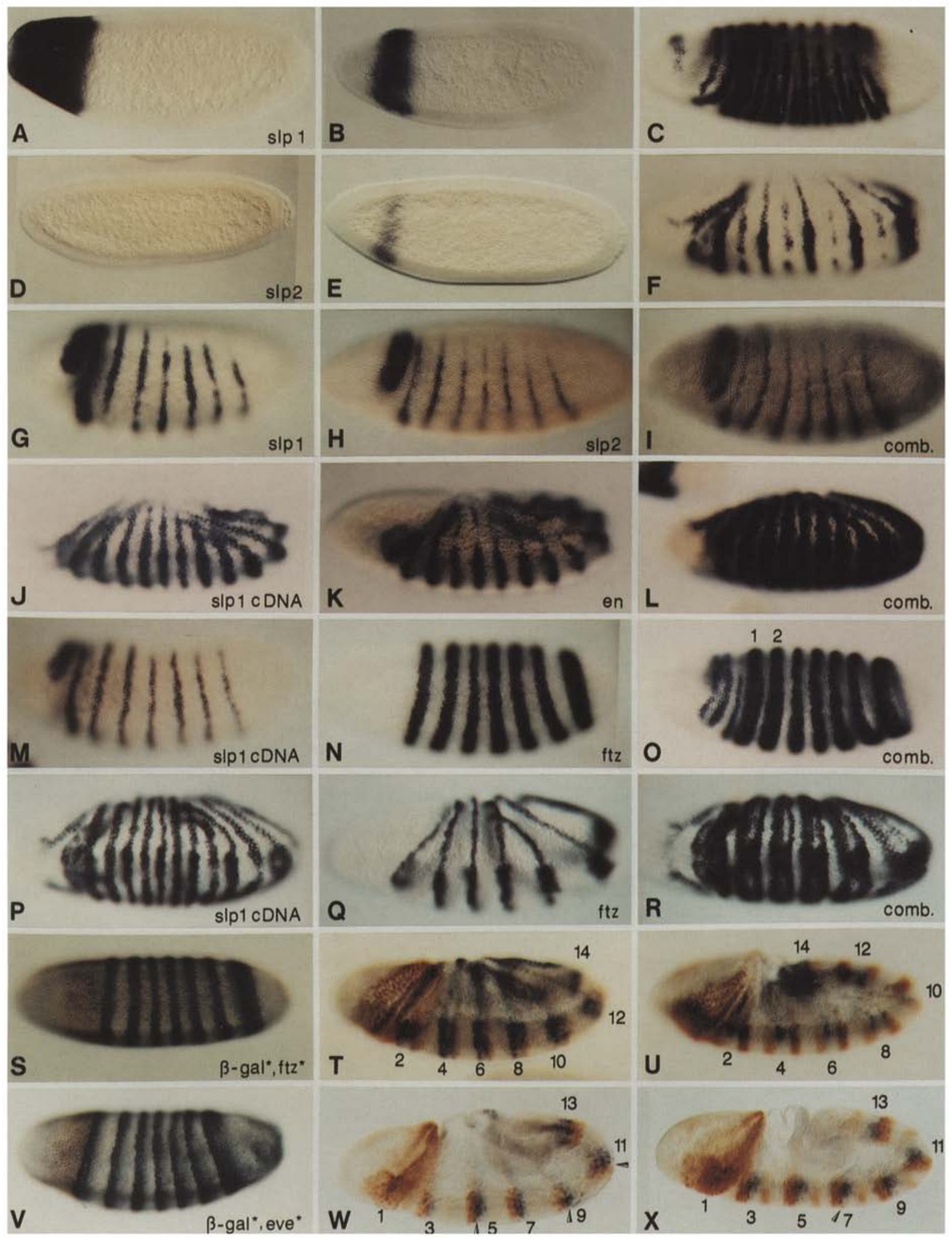

Figure 5. (See facing page for legend.) 


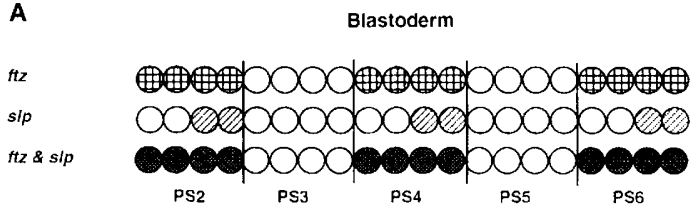

Early Gastrulation

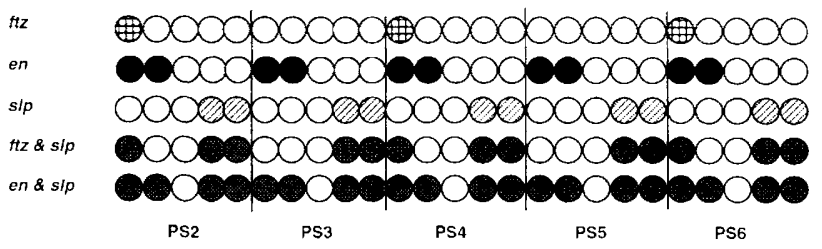

B

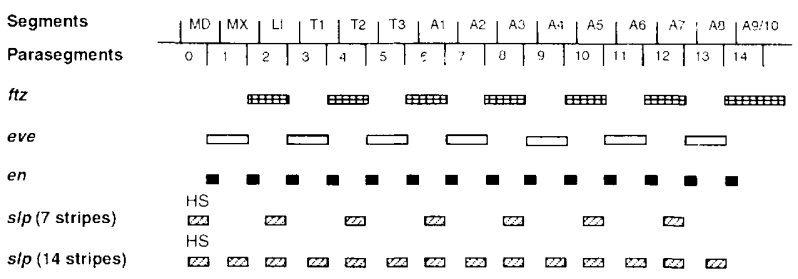

Figure 6. $s l p$ expression relative to other segmentation gene expression patterns. $(A)$ Idealized representation of five parasegments (PS) during early embryogenesis summarizing the results obtained by double in situ hybridizations. $f t z$ is expressed in the even-numbered parasegments originally in four cells (blastoderm). The posterior border of $f t z$ expression moves more anteriorly with progressing time such that only one cell expresses $f t z$ during gastrulation (Early Gastrulation). en is expressed in one to two cells demarcating the anterior part of each parasegment. slp is expressed in 7 and later in 14 stripes just anterior to the parasegmental boundary. Superimpositions of the expression patterns are shown. $(B)$ Expression domains of $s l p, f t z$, eve, and $e n$ at blastoderm. Primordia of gnathal (MD, mandibular; MX, maxillary; LI, labial), thoracic (Tl-3), and abdominal segments (Al-A9/10) are indicated. The initial domains of $f t z$, eve, $e n$, and slp expression are shown. Only 14 slp stripes are depicted. Two stripes anterior to the headstripe (HS) and the stripe at the tip of the extending germ band that develops later are not shown.

the three deletions $(\Delta 46 \mathrm{G}, \Delta 66 \mathrm{C}$, and $\Delta 34 \mathrm{~B}$; see Fig. 1A) the slp1 transcription unit is deleted and no slp1 expression can be detected. These rearrangements are, therefore, null alleles for $\operatorname{slp} 1$. With respect to $\operatorname{slp2}$, however, there are major differences between these alleles: in $\Delta 46 \mathrm{G}$ mutants $\operatorname{slp} 2$ is expressed normally suggesting that no regulatory sequences required for $\operatorname{slp} 2$ expression have been affected by this deletion. Embryos homozygous for $\triangle 66 \mathrm{C}$ show a strongly reduced and abnormal slp2 expression pattern during the first $10 \mathrm{hr}$ of development (until stage 13; Fig. 7D). Elements of the slp2 expression pattern that evolve later are present in $\Delta 66 \mathrm{C}$ mutant embryos. They are, however, irregular and disturbed as a result of segmentation defects. The deletion does not physically affect the $\operatorname{slp} 2$ transcription unit suggesting that sequences required for $\operatorname{sip} 2$ expression have been deleted in this allele. $\Delta 34 \mathrm{~B}$ is a large deletion re- moving slp1 and breaking in slp2. As expected, neither transcript can be detected in homozygous mutant embryos. $\triangle 34 \mathrm{~B}$ is, therefore, a null allele for both slp genes.

\section{Phenotypic analysis of segmentation defects} in slp mutants

The three original EMS-induced $s l p$ alleles show a mutant phenotype reminiscent of the pair-rule class of segmentation genes (Nüsslein-Volhard and Wieschaus 1980). The abnormalities in $s l p$ mutants can be described as partial deletions of naked cuticle in the odd-numbered abdominal segments and the mesothorax $(\mathrm{T} 2, \mathrm{~A} 1, \mathrm{~A} 3$, A5, A7) (Nüsslein-Volhard et al. 1984). The deletion of naked cuticle leads to the fusion of denticle belts from adjacent segments $(\mathrm{T} 2 / 3, \mathrm{~A} 1 / 2, \mathrm{~A} 3 / 4, \mathrm{~A} 5 / 6, \mathrm{~A} 7 / 8)$. In the affected segments the region covered with denticles is often expanded. Small regions of reversed or indeterminate polarity can be detected sometimes where pattern elements are juxtaposed, which are normally separate. We concentrated on the analysis of the ventral cuticle, but similar deletions as observed ventrally are also present dorsally (pattern deletions seem to be more consistent dorsally but are harder to analyze owing to lack of prominent cuticular markers).

The newly isolated slp alleles allowed us to identify new aspects of the slp phenotype. The alleles can be classified as weak (IIM105, $\Delta 41 \mathrm{E}, 7 \mathrm{~L} 48$, and 509), moderate $(\Delta 46 \mathrm{G})$, and strong $(\Delta 66 \mathrm{C}$ and $\Delta 34 \mathrm{~B})$. Cuticular phenotypes of larvae homozygous for one allele of each of these classes are shown in Figure 8. Because the expressivity of the slp phenotype is extremely variable we performed a semiquantitative analysis of the defects (Fig. $8 \mathrm{E})$. The histograms facilitate the classification of the alleles as weak, moderate, or strong. Please note that fusions of thoracic denticle belts are difficult to score (especially in weak mutants) and are, therefore, often underestimated.

The main characteristic of the weak alleles is that fusion of adjacent denticle belts is rarely complete and observed only in a few of the odd-numbered segments (Fig. $8 \mathrm{~B}, \mathrm{E})$. The only allele belonging to the moderate class, $\Delta 46 \mathrm{G}$, is an amorphic allele of $\operatorname{slp1}$ but does not affect slp2. $\Delta 46 \mathrm{G}$ shows the most consistent pair-rule phenotype where generally all or most of the odd-numbered segments show deletions (Fig. 8C,E). The even-numbered segments also show some defects but to a much reduced degree. The two strong alleles, $\Delta 66 \mathrm{C}$ and $\Delta 34 \mathrm{~B}$, in which both $s l p$ genes are affected, show a phenotype that is qualitatively different from $\Delta 46 \mathrm{G}$ (Fig. $8 \mathrm{D}, \mathrm{E}$ ); fusion of denticle belts from all segments leads to a large lawn of denticles (Fig. 8D). In both mutants the regions of reversed or indeterminate polarity are more prominent than in the weak and moderate alleles and may reflect true mirror image duplications. The phenotype, however, is clearly different from a classical segment polarity phenotype.

Two of the new slp alleles that we generated by remobilization of the enhancer detector transposon retained the lac $Z$ reporter gene $(\Delta 41 \mathrm{E}, \Delta 46 \mathrm{G})$. In these two alleles, 
Table 1. slp expression in slp mutants

\begin{tabular}{|c|c|c|c|c|c|c|c|}
\hline Mutant & $\mathrm{N}(\operatorname{slp} 1)$ & $\begin{array}{l}\text { Percent normal } \\
\text { slp1 expression }\end{array}$ & $\mathrm{N}(\operatorname{slp} 2)$ & $\begin{array}{l}\text { Percent normal } \\
\text { slp2 expression }\end{array}$ & slp1 & $\operatorname{sip} 2$ & Phenotype \\
\hline Or-R & 155 & 99 & 89 & 99 & + & + & wild type \\
\hline 208 & 441 & 99 & 587 & 100 & + & + & wild type \\
\hline IIM105 & 33 & 100 & 68 & 99 & + & + & weak \\
\hline $7 \mathrm{~L} 48$ & 60 & 98 & 153 & 99 & + & + & weak \\
\hline$\Delta 41 \mathrm{E}$ & 35 & 74 & 41 & 98 & $+1-$ & + & weak \\
\hline 509 & 122 & 77 & 68 & 97 & $+1-$ & + & weak \\
\hline$\Delta 46 \mathrm{G}$ & 38 & 74 & 66 & 97 & - & + & moderate \\
\hline$\Delta 66 \mathrm{C}$ & 92 & 73 & 206 & 76 & - & $+1-$ & strong \\
\hline$\Delta 34 \mathrm{~B}$ & 356 & 76 & 233 & 74 & - & - & strong \\
\hline
\end{tabular}

Embryos collected from balanced slp mutant stocks were hybridized in situ by use of specific probes for slp1 and $\operatorname{sip2}$. One-quarter of the embryos should be homozygous for the mutation; three-quarters should show normal expression of the $s l p$ genes. (N) Number of embryos scored; $|+|$ normal expression; $(+1-)$ abnormal, reduced expression; $|-|$ no expression. For mutants showing abnormal expression of one of the $s l p$ genes, only embryonic stages where the abnormality was clearly discernible were counted. The strength of the phenotype observed in embryos homozygous for each allele is indicated.

as well as in the insertional mutant 509 , the slp phenotype can already be monitored during embryogenesis using $\beta$-gal expression as a marker. Although some abnormalities of the expression pattern in the head region of the homozygous mutant embryos can be visualized at full germ band extension (see below), the segmental defects become only visible during germ-band shortening; the number of $\beta$-gal-expressing cells is greatly reduced in the odd-numbered abdominal segments, the mesothorax and the labial segment. The severity of the reduction correlates well with the strength of the corresponding allele (data not shown).

The molecular and phenotypic characterization of $\Delta 66 \mathrm{C}$ suggests that regulatory (probably enhancer) re- gions required for slp2 expression are deleted in this mutant. Southern blot analysis showed that the $5^{\prime}$ end of the enhancer detector transposon including a truncated $l a c Z$ gene is still present in $\Delta 66 \mathrm{C}$. If indeed enhancer elements are deleted from this chromosome one would expect to see an altered expression of the reporter gene not only in homozygous mutant but also in heterozygous embryos. As no protein could be detected using X-gal or a monoclonal antibody against $\beta$-gal we used a $l a c Z$ probe for in situ hybridization. Indeed, we could detect a strongly reduced abnormal signal in all embryos $(=120$ ) of stage 5-13 (Fig. 7E). The fact that lacZ expression is abnormal in both homozygous and heterozygous embryos suggests strongly that an enhancer element has
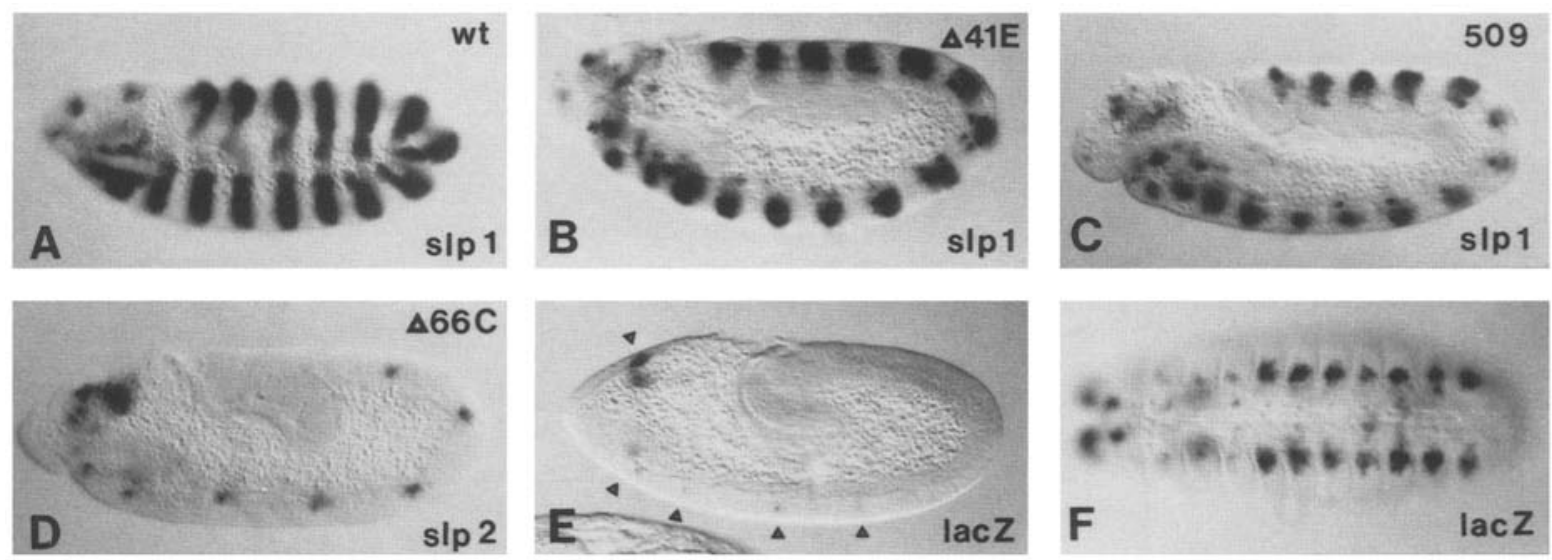

Figure 7. slp and lacZ mRNA distribution in wild-type and slp embryos. Whole-mount in situ hybridization was performed with digoxygenin-labeled probes. Mutant embryos were collected from balanced stocks. Approximately $25 \%$ of the progeny showed the depicted phenotype. All embryos are shown during germ band extension except where stated otherwise. The probes used are indicated in the lower right corner of each panel. $(A)$ Wild-type embryo. $(B) \Delta 41 \mathrm{E}$ homozygous embryo. The reduction of the staining is not as drastic as a comparison with $A$ suggests. The embryo shown is somewhat older than the wild-type embryo in $A$ and slp1 expression levels drop in lateral regions during this stage. $(C)$ Embryo homozygous for insertion $509 .(D) \Delta 66 \mathrm{C}$ homozygous embryo. (E) Both $\Delta 66 \mathrm{C}$ homozygous and heterozygous embryos show a strong reduction of $1 a c Z$ expression during early embryogenesis from blastoderm until germ band retraction. Triangles indicate small cell clusters expressing lacZ mRNA. $(F)$ Ventral view of embryos heterozygous for $\Delta 66 \mathrm{C}$ undergoing dorsal closure. 

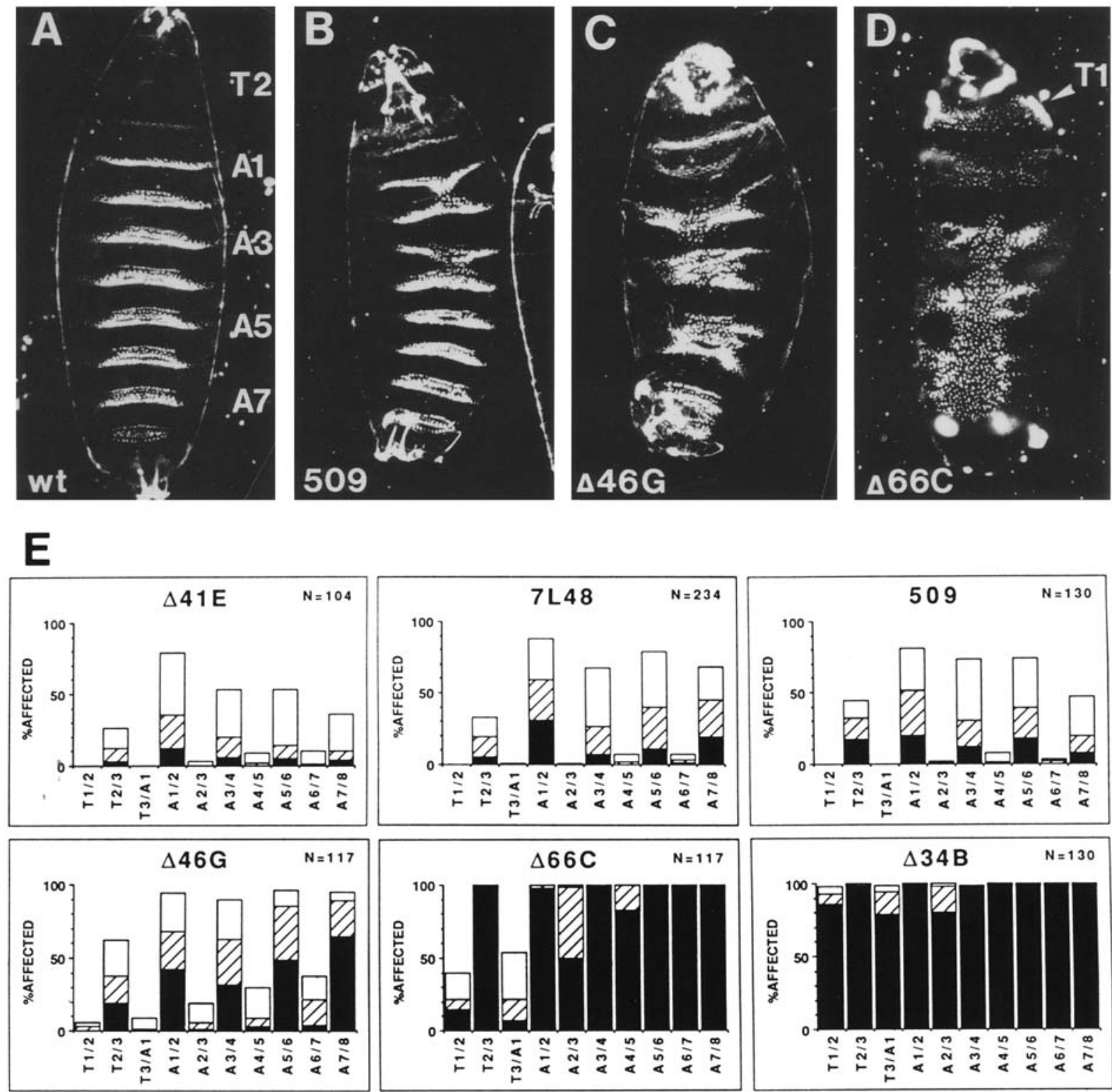

Figure 8. Cuticular phenotype of different $\operatorname{slp}$ alleles. Dark-field photomicrographs of cleared cuticular preparations of terminally developed embryos are shown. Anterior is uppermost. The allele is indicated at the bottom of each panel. (A) Wild type (wt). The anterior of each thoracic and abdominal segment (T2-A7) is marked with a characteristic denticle belt. $(B)$ Weak slp phenotype $(509)$. Partial fusions of adjacent denticle belts can be detected. Only a subset of the odd-numbered abdominal segments and the mesothorax show a deletion of nacked cuticle. In embryos homozygous for $\triangle 41 \mathrm{E}$ pattern elements are deleted only in one or two segments, for 509 and $7 \mathrm{~L} 48$ in two to three. $(C)$ Moderate $s l p$ phenotype. Larvae homozygous for $\Delta 46 \mathrm{G}$ show a classical pair-rule phenotype with fused denticle belts in every other segment. $(D)$ Strong slp phenotype. The denticle belts fuse to a single large denticle lawn. In $\Delta 66 \mathrm{C}$ the lawn is almost always interrupted between T3 and A1. Denticle belts of T2 and T3 are usually fused and the denticle belt of T1 is largely expanded in width (arrow) but separate from $T 2$. In $\triangle 34 \mathrm{~B}$ most often a complete fusion of all the denticle belts from $\mathrm{T} 1$ to $\mathrm{A} 8$ is observed (data not shown). In the few embryos with a low expressivity the phenotype is very similar to $\Delta 66 \mathrm{C}$. Generally the denticle belts in $\triangle 34 \mathrm{~B}$ homozygous mutants are fused along their entire length in contrast to those of $\Delta 66 \mathrm{C}$ where the fusions resulting from deletions in the even-numbered segments are often less complete than the ones resulting from deletions in odd-numbered segments. (E) Semiquantitative analysis of the cuticular phenotypes. Results are shown in the form of histograms. Larvae were scored for fusions of adjacent segments (T1/2, T2/3, etc.) and the degree of fusion was classified as slight if some sign of fusion (e.g., a row of denticles extending into the region of nacked cuticle) could be detected, but the belts were fused for less than one-quarter of their length (white columns). If the fusion covered between one-quarter and one-half of the length of a denticle belt the degree of fusion was classified as partial (hatched columns) and if it covered more than one-half as complete (black columns).

been affected by this deletion. As a consequence the lac $Z$ reporter gene is abnormally regulated in a way similar to slp2 in embryos homozygous for $\triangle 66 \mathrm{C}$. At later stages of embryogenesis only one-third of the lacZ-expressing em- 
bryos show abnormal patterns, whereas the remaining two-thirds look normal ( = 63) (Fig. 7F). Abnormalities are, therefore, only seen in embryos homozygous for the mutation that also show segmentation defects. These observations suggest that, in contrast to enhancer elements required for the early expression of slp2, regulatory elements playing a role in controlling the late expression are not affected by $\Delta 66 \mathrm{C}$.

\section{Head defects in slp embryos}

During stages 13 and 14 of Drosophila embryogenesis (Campos-Ortega and Hartenstein 1985) the complex process of head involution takes place: The six lobes of the head (labial, maxillary, mandibular, hypopharyngeal, procephalic, and clypeolabral) migrate through the stomodeal opening (Turner and Mahowald 1979). After involution the ectodermal cells of the head lobes form the cuticular and sensory structures of the head including the cephalopharyngeal skeleton (CPS), labrum (lr), mouth hooks (MH), cirri (ci), and antennal and maxillary sense organs (AntSO, MxSO) (Fig. 9A,E). The correct secretion and morphology of these structures depends on proper juxtaposition and fusion of the involuted head lobes.

Embryos homozygous for moderate $(\Delta 46 \mathrm{G})$ and strong slp alleles $(\Delta 66 \mathrm{C}, \Delta 34 \mathrm{~B})$ exhibit strong defects in the head region. The head lobes fail to involute and, consequently, the head skeleton does not form properly. It is, therefore, not possible to discriminate between primary and secondary defects resulting from a failure of head involution. Embryos homozygous for $\triangle 46 \mathrm{G}$ showing a low expressivity of the phenotype, however, provide some infomation: Structures derived from the maxillary (ci, MH, MxSO), intercalary posterior wall of pharynx (ppw), antennal segment (AnSO), and derivatives of the acron [dorsal bridge $(\mathrm{DBr}\}$, dorsal arm $(\mathrm{DA})$, and vertical piece (VP)] can be detected, but lateralgräten (LG) and ventral arms (VA) of the CPS derived from the mandibular segment are always missing (data not shown).

Particularly useful for the determination of the head defects in slp embryos are the weak alleles where head involution occurs and the CPS develops. In these mutants the only structures of the CPS that are missing or reduced are derived from the mandibular (VA and LG) and the labial segment [bridge of the H-piece $(\mathrm{H})$; Fig $9 \mathrm{~F}$ ]. The LG are present in larvae homozygous for $\triangle 41 \mathrm{E}$ (Fig. 9B,F) and 509 (Fig. 9C) but are reduced in length. In mutants homozygous for either allele the VA of the CPS are present although they may be reduced (especially in $\Delta 41 \mathrm{E}$ ). In $7 \mathrm{~L} 48$ homozygous embryos the LG are missing completely from the CPS and also the VA are generally deleted (Fig. 9D). The expressivity of the slp phenotype in the head varies to a large extent such that some structures of the CPS may be present in one embryo but absent in another.

The slp1 null allele, $\Delta 46 \mathrm{G}$, retained the $1 a c Z$ gene such that $\beta$-gal can be used to monitor the mutant phenotype in the head of the developing embryo. In heterozygous embryos we observe the wild-type situation: The six lobes of the head express $\beta$-gal at germ-band extension (Fig. $9 \mathrm{H}$ ). In embryos homozygous for $\Delta 46 \mathrm{G}$ the expression in the mandibular lobe is missing (Fig. 9I), whereas $\beta$-gal is expressed normally in the other head lobes. A similar result was obtained by in situ hybridizations using $e n$ as a probe, a good marker for head segments (DiNardo et al. 1985; Cohen and Jürgens 1990; Finkelstein and Perrimon 1990). The en expression pattern is abnormal in $\Delta 46 G$ and $\triangle 34 B$ mutants, but all pattern elements except for the expression in the mandibular segment primordium can be identified (data not shown). These observations suggest that in slp1 mutant embryos the mandibular lobe is absent and, therefore, slp1 activity is required for its formation. Because single segments are affected rather than several adjacent ones, we do not interpret this phenotype as that of a gap mutation. In contrast, $\beta$-gal expression in the labial segment of homozygous $\Delta 46 \mathrm{G}$ embryos is normal at the extended germ band stage and shows a reduction in the number of $\beta$-gal expressing cells only during germ band retraction. A similar reduction is observed in the mesothorax and in the odd-numbered abdominal segments (see also Fig. 10D).

\section{Complementation analysis}

The phenotypic analysis of the different $s l p$ alleles showed that both transcription units of the locus are contributing to the phenotype. In mutants where only slp1 is affected the classical pair-rule phenotype is observed. If, however, both transcription units, slp1 and slp2 are affected we observe a qualitatively different phenotype, namely, pattern deletions in all segments leading to a denticle lawn. To gain more insight into the roles of the two transcription units we performed a complementation analysis with all available $s l p$ alleles. Terminally developed embryos were scored for denticle belt fusions and the phenotype of trans-heterozygous combinations during embryogenesis was examined where at least one of the alleles was producing $\beta$-gal. Selected examples are shown in Figure 10. We could establish a more precise allelic series: IIM105 $<\Delta 41 \mathrm{E}<509<$ 7 L48 $<\Delta 46 \mathrm{G}<\Delta 66 \mathrm{C}<\Delta 34 \mathrm{~B}$, with IIM105 being the weakest allele.

Mutants trans-heterozygous for any two of the weak alleles (IIM105, $\Delta 41 \mathrm{E}, 7 \mathrm{~L} 48$, and 509) exhibit a weak phenotype (Fig. 10H,N; cf. with histograms in Fig. 8E). All of the weak alleles give a stronger, more consistent pairrule phenotype if they are in trans over the $\Delta 46 \mathrm{G}$ deletion that removes sIp1 completely, showing that they are hypomorphic alleles of slp1 (Fig. 10I,O). In mutants trans-heterozygous for a weak or moderate allele $\left(\operatorname{sip} 1^{-}\right.$ $\left.\operatorname{slp2^{+}}\right)$ and a strong allele $\left(\operatorname{slp} 1^{-} \operatorname{slp} 2^{-} ; \Delta 66 \mathrm{C}, \Delta 34 \mathrm{~B}\right)$ we observe an intermediate phenotype. All of the odd-numbered segments show partial or complete deletions of the naked cuticle and some of the even-numbered segments are also affected (Fig. 10K,Q,L,R). This intermediate phenotype lies in strength between the moderate pair-rule (Fig. 10J,P) and the strong denticle lawn phenotype (see Fig. 8D,E). The presence of intermediate phenotypes in these combinations demonstrates that one copy of slp2 

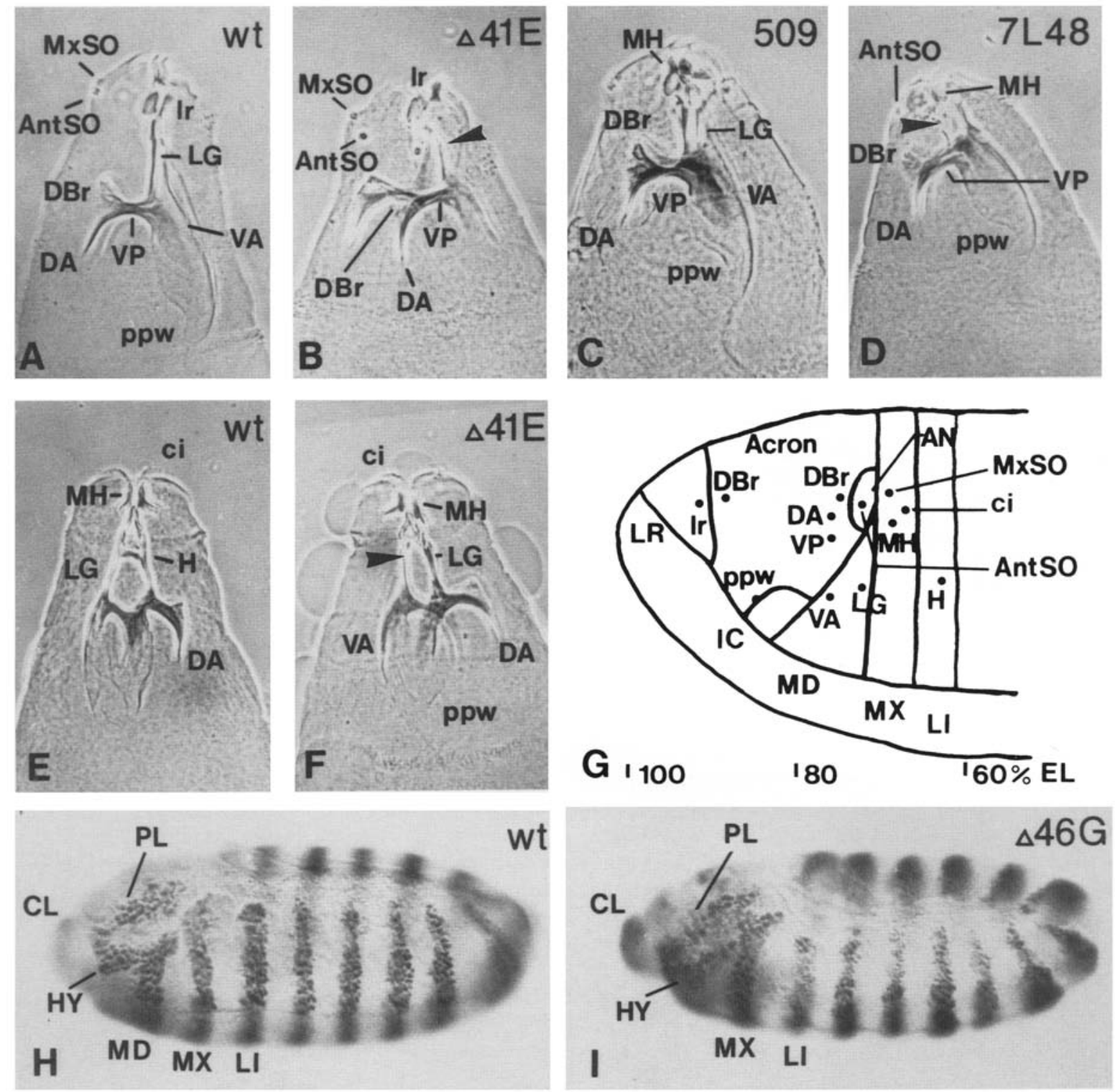

Figure 9. Head defects in slp embryos. Phase-contrast photomicrographs of the head of terminally developed embryos as seen in cleared and flattened cuticle preparations are shown $(A-F)$. Transposant embryos that were stained with anti- $\beta$-gal antibody are shown in $H, I .(A, E)$ Head structures of a wild-type larva, lateral and dorsal view, respectively. $(B, F)$ In $\Delta 41$ larvae the lateralgräten (LG) are shortened $(B$, arrowhead) and the bridge of the $\mathrm{H}$ piece $(\mathrm{H})$ is absent $(F$, arrowhead). $(C)$ In larvae homozygous for 509 the LG are strongly reduced. (D) 7L48 mutants miss the LG (arrowhead) and the ventral arms (VA). (G) Diagram of a blastoderm fate map for head structures according to Jürgens et al. (1986). Only primordia of structures that were scored in our analysis are included. $(H) \mathrm{A} \Delta 46 \mathrm{G}$ heterozygous embryo shows the wild-type $\beta$-gal expression pattern at germ band extension. Note the stripe-like expression in the procephalic lobe (PL) and the hypopharyngeal (HY), mandibular (MD), maxillary (MX), and labial (LI) segment primordia. Expression in the clypeolabrum $(\mathrm{CL})$ is only faintly visible in this focal plain. $(I)$ In $\Delta 46 \mathrm{G}$ homozygous embryos the expression in the head region is affected, whereas no abnormalities can be detected in thoracic and abdominal segments at this stage. Two parallel stripes in the procephalic lobe and the hypopharyngeal segment primordium are present. Expression in the maxillary and labial segment is normal but no staining is detectable in the mandibular segment. (DBr) Dorsal bridge; (DA) dorsal arm; (VP) vertical piece; (ci) cirri; (MH) mouth hooks; (AntSO and MxSO) antennal and maxillary sense organs; (lr) labrum; (ppw) posterior wall of pharynx; (LR) labral; (IC) intercalary segment primordia.

alone is insufficient to ensure proper segmentation of the even-numbered abdominal segments in a $\operatorname{slp1^{-}}$ background. On the other hand, the two genes are not equivalent as only one copy of each is required for viability ( $\Delta 34 \mathrm{~B}$ heterozygotes are viable).
The phenotypic characterization of homozygous and trans-heterozygous combinations of different $s l p$ alleles revealed that there is a graded regional specificity of the phenotype such that the frequency and severity of the deletions varies from segment to segment. Of the odd- 

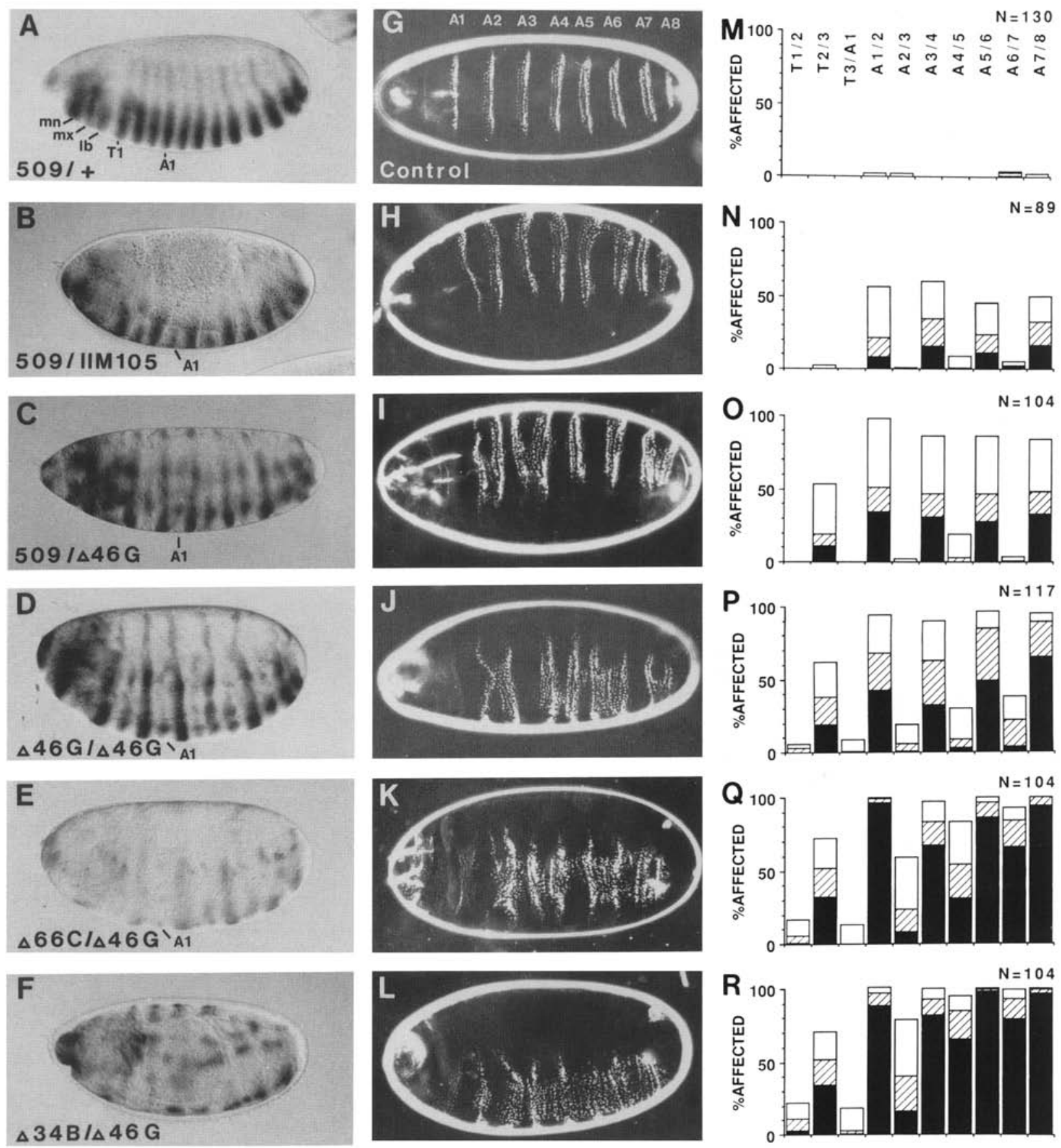

Figure 10. Complementation analysis illustrated by $\beta$-gal expression, cuticular phenotype, and histograms. We analyzed $\beta$-gal activity in mutant embryos using the chromogenic substrate $\mathrm{X}$-gal . All embryos shown have undergone germ band retraction $\langle A-F\rangle$. The cuticular phenotype of terminally developed embryos of the corresponding genotype is shown in the second column (G-L) and the semiquantitative analysis of each cross in the last column $(M-R$; cf. Fig. $8 \mathrm{E})$. The genotype is given in the left corner of each panel in the first column. Decreasing $\beta$-gal activity from $A-F$ correlates well with an increasing strength of the phenotype from $G$ to $L$. $(B-D)$ In trans-heterozygous combinations showing a weak to moderate phenotype $\beta$-gal activity in odd-numbered abdominal segments, the mesothorax and the labial lobe $(\mathrm{lb})$ is reduced. $(E, F)$ In embryos exhibiting a stronger phenotype the other stripes are also affected. Note the typical intermediate phenotype in $K$. Some embryos with only one functional slp2 gene $(\Delta 34 \mathrm{~B} / \Delta 46 \mathrm{G})$ with a high expressivity of the phenotype look very similar to slp1 slp2 double mutants (L). Mandibular $(\mathrm{mn})$ and maxillary $(\mathrm{mx})$ segment.

numbered abdominal segments that are affected in $\operatorname{slp} 1$ mutants generally Al has the highest probability to be affected by deletions; then $\mathrm{A} 7, \mathrm{~A} 5$, and $\mathrm{A} 3$ follow in decreasing order. Of the even-numbered segments that are 
affected in larvae lacking slp1 and slp2, A6 is most often affected; then A4, A2, and T3. Thus, different levels of $s l p$ activity seem to be required in different segments.

\section{Discussion}

Enhancer detection is a powerful method to combine molecular and classical genetics

Genes identified by enhancer detection can be analyzed easily genetically by remobilization of the enhancer detector transposon and screening for imprecise excisions causing a mutant phenotype (e.g., Bellen et al. 1989; Grossniklaus et al. 1989; Fasano et al. 1991). Several advantages result from a genetic analysis that is coupled to enhancer detection. First, jumpouts displaying a homozygous mutant phenotype are recovered at high frequency. Mobilization of the viable insertion 208 created $\sim 30 \%$ lethal jumpouts (see Materials and methods). Frequencies between 30 and $50 \%$ were also recovered in other experiments using $\mathrm{P}[\mathrm{lArB}]$ (Grossniklaus et al. 1989; U. Grossniklaus, unpubl.). Second, rather large deletions can be recovered. The four revertants we analyzed molecularly had rearrangements encompassing $\geqslant 10 \mathrm{~kb}$. As we only analyzed rearrangements affecting slp1, we do not know anything about the molecular nature of the remaining 143 lethal jumpouts presumably affecting slp2 (see Materials and methods). Nevertheless, the lower limit for the recovery of sizable rearrangements is in the order of $1 \%$. Third, terminal parts of $\mathrm{P}[\mathrm{lArB}]$ are sometimes left behind. This is especially useful if the $l a c Z$ reporter gene is not deleted. $\beta$-Gal can then be used to monitor expression during development in mutant embryos. Two of the four rearrangements we tested retained $\beta$-gal activity and one carried a truncated $l a c Z$ gene (frequencies of $15-50 \%$ were also found in other experiments; U. Grossniklaus, unpubl.). Moreover, sequences at the $3^{\prime}$ end of $\mathrm{P}[\mathrm{lArB}]$ including the Bluescript vector were still present in two of the four jumpout alleles. Thus, rearrangement breakpoints could be cloned easily by plasmid rescue and could be sequenced directly.

\section{The fork head domains of the slp genes define a new} subfamily

The slp proteins contain a novel putative DNA-binding domain, the fork head domain (Weigel and Jäckle 1990), that is also present in the Drosophila homeotic protein fork head (Weigel et al. 1989) and three rat hepatocyte transcription factors of the HNF-3 family (Lai et al. 1990, 1991). The fork head domains of these six proteins can be divided into two subfamilies (Fig. 3B): The proteins of the $f k h$ subfamily ( $f k h$ and the HNF-3 factors) show homology in the order of $90 \%$ over a stretch of 110 amino acids. The fork head domains in the two proteins of the slp subfamily (slp1 and $\operatorname{sip} 2$ ) are much more homologous to each other $(-75 \%)$ than to the ones found in the $f \mathrm{kh}$ subfamily $(\sim 50 \%)$ and show differences at both termini. Whereas the amino-terminal part contains several in- variant blocks (Fig. 3B; residues 11-16: KPPYSY, 55-61: WQNSIRH, 79-92: PGKG), the carboxy-terminal end of the domains shows little homology between the two subfamilies. In addition to the fork head domain two small regions (II and III; Lai et al. 1991) are conserved among all proteins (Fig. 3B). The carboxy-terminal position of these regions in the $f k h$ subfamily has not been conserved in the slp proteins substantiating our classification of the fork head domain proteins into two subfamilies (Fig. 3C).

The slp locus exhibits characteristics of all three segmentation gene classes

The metameric pattern of the Drosophila embryo is established through a hierarchy of controlling genes and regulation primarily occurs at the transcriptional level. Consistent with a function in this cascade, the slp proteins encode a putative DNA-binding domain, strongly suggesting that they are transcriptional regulators. The slp transcripts accumulate during early embryogenesis in three steps, each showing characteristics of one of the segmentation gene classes, the gap, pair-rule, and segment polarity genes.

First, slp1 mRNA starts to be expressed in a region covering the anterior-most quarter of the embryo (Fig. 4A). This expression pattern in the head narrows in a first phase to a ring that encompasses more than one segment primordium (Fig. 4B). This early expression of slp1 in a broad region is reminiscent of the gap gene class. Moreover, slp1 is expressed as early as other gap genes such as Krüppel (Knipple et al. 1985) and hunchback (Tautz et al. 1987). In a second phase the broad head ring evolves into a narrow circumferential stripe roughly corresponding to the mandibular segment primordium and a more anterior cap (Fig. 4E). A similar development of the expression pattern has been described for the gap gene giant (Eldon and Pirotta 1991; Kraut and Lewine 1991). Although the temporal and spatial expression pattern of slp1 shows some characteristics of the gap gene class, the phenotype we observe in the head of terminally developed embryos does not. Embryos homozygous for hypomorphic slp1 alleles show only a deletion or reduction of structures derived from individual segments (mandibular and labial). We believe that deletions of head structures of mandibular or labial origin, respectively, are qualitatively different, because we can detect defects in the mandibular segment much earlier than defects in the labial, thoracic, and abdominal segments. Thus, only the mandibular segment is affected in slp mutants during early embryogenesis. This phenotype correlates well with the second phase of head expression, whereas the functional significance of the early gap genelike expression is obscure. Two other pair-rule genes, odd-skipped (odd) and paired (prd) are also initially expressed in a single anterior ring (Kilchherr et al. 1986; Coulter et al. 1990). In odd and prd mutant embryos head structures are deleted (Nüsslein-Volhard et al. 1985; Coulter and Wieschaus 1988) and the deleted structures roughly correlate with the early expression. 
In the second step, six primary stripes are added to the head stripe yielding a pattern of seven periodic stripes (Fig. 4G). This represents the double segment pattern observed in all pair-rule genes analyzed and corresponds to the pair-rule phenotype of hypomorphic and amorphic slp1 mutants. Although most pair-rule genes are initially expressed in a broad graded or uniform pattern that resolves into stripes by loss of transcripts from intervening gaps (ftz; Hafen et al. 1984; hairy, Ingham et al. 1985; eve, Macdonald et al. 1986; runt, Gergen and Butler 1988; odd, Coulter et al. 1990), prd (Kilchherr et al. $1986)$, and $s l p$ transcripts accumulate by de novo transcription as discrete bands.

Finally, in a third step, seven secondary stripes are added at the end of cellular blastoderm resulting in a metameric pattern with a one segment periodicity (Fig. $4 \mathrm{M}$ ), reminiscent of some of the segment polarity genes (en, Fjose et al. 1985; Kornberg et al. 1985; wg, Baker 1987; gsb, Baumgartner et al. 1987; Côté et al. 1987). slp is not the only pair-rule gene that shows a transition in the metameric pattern from a two-segment to a one-segment periodicity. Although with prd this doubling process is very complex and involves a splitting of broad primary stripes, in odd, eve, runt, and slp the secondary stripes are generated by de novo synthesis and accumulate to the level of the primary stripes (except for the secondary eve stripes that remain extremely faint). Although expression levels of the other characterized pairrule genes drop dramatically during germ band extension, slp expression is maintained much longer and the epidermal stripes only fade after the germ band has retracted. Such prolonged maintenance of $s l p$ expression is reminiscent of some of the segment polarity genes. What do we know about the role of these single-segment expression patterns exhibited by most pair-rule genes? The qualitatively different phenotype we observe in slp1 (pair-rule) versus slp1 slp2 (denticle lawn) null mutants argues that slp2 plays a role in every segment or at least in the segments that are not affected by slp1 null mutants. The phenotypes of prd, odd, and runt, however, give no indication that these genes may be required in every segment. In eve null alleles, on the other hand, engrailed is not expressed at all indicating a requirement in every segment (Harding et al. 1986; Macdonald et al. 1986; DiNardo and O'Farrell 1987). Another observation substantiates that the $s l p$ locus is required to generate homologous patterns within every segment: Different levels of $s l p$ activity are required in different segments. For both even-numbered and odd-numbered segments, there is a posterior to anterior gradient for the requirement of slp activity: The most posterior segments need the highest levels of $s l p$ activity, decreasing activities are needed in more posterior segments; the only exception being $\mathrm{Al}$, which is the most sensitive of the odd-numbered segments. This gradient is nicely reflected by the temporal anterior to posterior gradient in which both primary and secondary stripes evolve. The most posterior stripes evolve last and correspond to the segments that are the most sensitive to lowered levels of $s l p$ activity. Furthermore, we observed that the third of the primary stripes is consistently weaker than the others. This stripe falls into the segment primordia for Al (Fig. 6B) correlating well with the extreme sensitivity of Al to changes of $s l p$ activity.

The two slp genes may be controlled by a common enhancer element

Several loci consisting of two structurally related genes have been described. The two genes of such a locus are either expressed in virtually identical patterns or show at least a considerable overlap of expression patterns. Two alternative hypotheses could explain the striking similarities of the expression patterns. Either each gene has similar regulatory sequences or the two genes are controlled by common enhancer-like elements. We isolated two enhancer detector insertions in the slp locus. The expression patterns of the lac $Z$ reporter gene in both insertion lines and of the two slp genes are qualitatively identical only showing temporal and quantitative differences. The expression of these genes is controlled by one or more enhancer-like elements that are part of the $s l p$ regulatory region. These cis-regulatory sequences behave as true enhancers. They act on the heterologous P promoter that controls the reporter gene in an orientationand distance-independent manner (Fig. 1A). Several lines of evidence suggest that these enhancer elements are located to the right of the slp1 transcription unit (Fig. 1A). First, the two insertions do not express $\beta$-gal at the same level. Insertion 509 shows much higher levels of expression than insertion 208. If sequences covering the distance between these two insertions are removed (as in $\Delta 46 G$; Fig. 1A) the reporter gene of insertion 208 is expressed at a similar level as in 509 (data not shown). These findings indicate that $\beta$-gal activity decreases with increasing distance between the enhancer elements and the reporter gene. On the basis of these results the enhancer elements should lie closer to 509 than to 208 . Because they are functional in the deletion $\Delta 46 \mathrm{G}$, they have to be placed to the right of slp1 (Fig. 2A). However, we do not observe a reduction of $\operatorname{sip} 2$ expression levels in 208 (where $\sim 20 \mathrm{~kb}$ are inserted between $\operatorname{slp} 1$ and slp2) suggesting that the $\operatorname{sip} 2$ promoter is less sensitive to distance effects than the P-transposase promoter driving lacZ. Second, genetic and molecular evidence showed that $s l p 2$ is nonfunctional in $\Delta 66 \mathrm{C}$, although slp2 is not physically affected by this deletion. Moreover, the expression of the truncated reporter gene in $\triangle 66 \mathrm{C}$ is abnormal not only in homozygous but also in heterozygous nonmutant embryos. As the reporter gene supposedly reflects the action that enhancer elements confer on its promoter, some of these elements should be deleted in $\Delta 66 \mathrm{C}$. The only genomic sequences that are affected in $\Delta 66 \mathrm{C}$ but not in $\Delta 46 \mathrm{G}$ (in which slp2 and the enhancer elements are functional) lie to the right of $s l p 1$. If the $s l p$ genes are indeed controlled by common enhancer elements in the slp1 upstream region, this would mean that certain enhancers cannot only confer their activity onto the next adjacent promoter but also across this adjacent gene onto a second promoter. A related phenomenon has 
been described for the human $\beta$-like globin genes that are organized as a cluster $\left(\epsilon \gamma^{\mathrm{G}} \gamma^{\mathrm{A}} \delta \beta\right)$ in an order that reflects their developmental expression. The entire set of $\beta$-like globin genes is controlled by the locus control region (LCR) situated $5^{\prime}$ of the $\epsilon$-gene (Forrester et al. 1987; Grosveld et al. 1987).

How are the genes of other two-gene complexes regulated? Whereas the genes of the sry locus are controlled by their own individual set of regulatory sequences (Payre et al. 1990), the yp genes share common enhancer elements that direct tissue-specific expression of the two divergently transcribed genes (Garabedian et al. 1985). Control regions of en (Kassis 1990) and $z 1$ (Doyle et al. 1989) have been identified as well but it is unknown whether they also act on inv and z2, respectively. Several of these loci show temporal differences in the expression of the two genes similar to what we observe for slp len and inv, Coleman et al. 1987; sry $\beta$ and sryo, Payre et al. 1990; gsb-proximal and gsb-distal, Baumgartner et al. 1987). The reason for this difference is unknown but an intriguing possibility is that the temporal delay may be coupled to the distance between the gene and the enhancer. That the relative distance between a gene and its regulatory sequences can indeed be important for its temporal regulation has been shown for the globin locus where the gene order, and therefore, the relative distance to the LCR is important for correct developmental expression of the $\beta$-like globin genes (Hanscombe et al. 1991).

\section{Functional relationship between the slp genes}

The conserved structure and the similarity of expression patterns of the genes in a two-gene complex supports their evolutionary relationship. Such common ancestry also suggests that the two genes should be functionally related. For $s l p$ we could demonstrate that both genes are contributing to the phenotype and are involved in the segmentation of the embryo. The recovery of a large number of lethal jumpouts, of which only four are affecting $\operatorname{slp} 1$ (see Materials and methods), suggests that both $s l p$ genes are essential. We propose that $\operatorname{slp} 1$ is a classical pair-rule gene, whereas $s l p 2$ may function primarily as a segment polarity gene. Consistent with this hypothesis slp2 is expressed at a later stage than slp1. Furthermore, we often see regions of indeterminate or reversed polarity in $s l p$ mutants. These polarity reversals are not as consistent as in segment polarity mutants or the pairrule mutants runt and odd, but become quite prominent in slp1 slp2 double mutant embryos. The strong phenotype we observe, however, cannot be explained by a simple superimposition of a pair-rule and a segment polarity mutation. Mutations in the slp genes do not behave in an additive fashion because they show a genetic interaction: Removal of one copy of slp2 in an slp1- background leads to an intermediate phenotype. The isolation of new alleles that exclusively affect slp 2 and a functional dissection of the two proteins should allow us to discriminate between the roles of $\operatorname{sip} 1$ and $\operatorname{slp} 2$ during segmentation and to investigate their functional interaction in more detail.

\section{Materials and methods}

Fly stocks, mutagenesis, and cuticle preparations

The three originally isolated $s l p$ stocks $\left(s 1 p^{L 12} / C y O ; s l p^{I I M 105} \mathrm{cn}\right.$ bw sp/CyO; slp ${ }^{7 L 48} / C y O$ ) and Df(2L)ed $d^{S Z 1}$ al b/SM5 (Reuter and Szidonya 1983/ were kindly provided by C. Nüsslein-Volhard and are described in the Tübingen stock list (Tearle and Nüsslein-Volhard 1987). slp $p^{7 L 48}$ and $D f(2 L) e d^{S Z 1 a l}$ al $b$ were rebalanced over the CyRoi balancer chromosome derived from stock $D f(2 L) s c^{19-1} / C y R o i$, which was a gift from J. Szidonya. $s p^{112}$ has lost the slp mutation. The homozygous phenotype of $s l p^{I I M 105}$ could not be assessed, as no proper cuticle was formed in these mutants. $\mathrm{P}[\mathrm{Ar} \mathrm{A}] \mathrm{A} 208.1 \mathrm{M} 2$ and $\mathrm{P}[\mathrm{IArB}] \mathrm{A} 509.1 \mathrm{~F} 2$ were isolated in an enhancer detector screen (Bellen et al. 1989). Additional slp alleles were generated by remobilization of $\mathrm{P}[1 \mathrm{ArB} \mid \mathrm{A} 208.1 \mathrm{M} 2$. Jumping-out of the insertion could be detected by the loss of the $r y^{+}$eye color after introducing a stable constitutive source of P-transposase (Robertson et al. 1988) into the transposant. CyO P[1ArB]A208.1M2/b Adh cn 1(2); ry r $^{506 /}$ $r y^{506}$ males were crossed to $\mathrm{CyO} / \mathrm{Sp}$; ry ${ }^{506} \mathrm{Sb} \mathrm{P}\left[\mathrm{ry}{ }^{+} \Delta 2-3\right](99 \mathrm{~B}) /$ TM6 females. One-hundred crosses of CyO P[1ArB]A208.1M2/ $S p ; r y^{506} S b \mathrm{P}\left[r y^{+} \Delta 2-3\right]\left[(99 \mathrm{~B}) / r y^{506}\right.$ males to $r y^{506} / r y^{506}$ females were set up and five male $r y^{-}$revertants from each, of the genotype CyO $\triangle \mathrm{XY} \mathrm{P}[\mathrm{lArB}] \mathrm{A} 208.1 \mathrm{M} 2 /+$; $\mathrm{ry}^{506} / \mathrm{ry}^{506}$, were individually backcrossed to $r y^{506} / \mathrm{ry}^{506}$ females. These 500 males were subsequently crossed to $D f(2 L) e d^{S Z 1} / C y R o i$ females to test for lethality. $D f(2 L) e d^{S Z 1}$ is a deletion uncovering the $s l p$ locus. Of the $r y^{-}$jumpout progeny 147 were lethal over $D f(2 L) e d^{S Z 1}(\sim 30 \%)$. They were further tested by crossing them to $s p^{7 L 48} /$ CyRoi flies. Only four strains $(\Delta 34 \mathrm{~B}, \Delta 41 \mathrm{E}, \Delta 46 \mathrm{G}$, and $\triangle 66 \mathrm{C}$ ) were found to carry a $C y O$ chromosome that was lethal over the $s p^{7 L 48}$ chromosome. As the original EMS-induced alleles are most probably allelic to $\operatorname{slp} 1$ (based on phenotype and complementation), slp2 mutants were not picked up by this screening method. It is very likely that most of the remaining 143 lethal jumpouts were allelic to $\operatorname{slp2}$. Cuticles were prepared for microscopic examination as described by Nüsslein-Volhard et al. (1984).

\section{Cloning and molecular characterization of the slp locus}

Genomic DNA adjacent to the $3^{\prime}$ end of P[1ArB|A208.1M2 was cloned by plasmid rescue (Wilson et al. 1989) and used to isolate genomic phages from a Canton-S wild-type library (Maniatis et al. 1978). Poly(A) ${ }^{+}$RNA preparations from all developmental stages and Northern blot analysis were performed as described by Wilson et al. (1989). Genomic DNA from mutant and control stocks for molecular mapping of the rearrangements was isolated as described by Wilson et al. (1989). All recombinant DNA techniques can be found in Sambrook et al. (1989). Labeling reactions were done using the multiprime DNA-labeling system (Amersham) according to the manufacturer's instructions.

\section{cDNA isolation and sequencing of $c D N A$ and genomic clones}

To isolate cDNA phages encoding the $\operatorname{sip} 1$ transcription unit we used the 6.2-kb EcoRI (RI) fragment (Fig.1A) to screen the 3- to 12-hr embryonic $\lambda$ gt 10 cDNA library of L. Kauvar (Poole et al. 1985). We recovered 11 cDNA clones that fall into four size classes. The 2.3-kb RI and the 2.6-kb RI fragments, both of which hybridized to the slp 2 transcription unit on a developmental Northern blot, were used as a combined probe to isolate 
cDNA clones encoding slp2. We screened a random primed embryonic (0-24 hr) $\lambda g t 11$ cDNA library (a kind gift of B. Hovemann) and recovered nine cDNAs falling into three size classes. The longest slp 1 and slp 2 cDNAs and genomic fragments encoding the slp1 and slp2 RNA were subcloned into BluescriptKS (Stratagene) in both directions. Nested deletions of the clones were made using ExoIII and $\mathrm{S} 1$ nucleases (doublestranded nested deletion kit; Pharmacia). Both strands of $\operatorname{sip} 1$ and slp 2 cDNA and of corresponding genomic regions were sequenced using dideoxy nucleotides and T7 DNA-polymerase (Pharmacia) according to the instructions of the manufacturer. The Sequenase DNA-sequencing kit (U.S. Biochemical) was used to sequence certain regions with deoxy-inosin-triphosphate (dITP).

Jumpout alleles $\triangle 41 \mathrm{E}$ and $\Delta 46 \mathrm{G}$ retained Bluescript sequences and, therefore, adjacent genomic DNA could be isolated by plasmid rescue. Small fragments adjacent to the $3^{\prime}$ end of the rearranged $\mathrm{P}$ elements were subcloned and sequenced to determine the breakpoints of these two rearrangements and the insertion P[1ArB]A509.1F2. Double-stranded sequencing using T7 and T3 primers (Stratagene) was performed following a protocol provided by Pharmacia. Sequence analysis was performed on the VAX with the University of Wisconsin GCG programs (Devereux et al. 1984). The homology search of the EMBL data bank was carried out with the FASTA and TFASTA programs (Pearson and Lipman 1988).

\section{Analysis of expression patterns}

$\mathrm{X}$-gal stainings for $\beta$-gal activity in whole-mount embryos were performed as described by Bellen et al. (1989).

In situ hybridization to whole-mount embryos using digoxygenin-labeled probes was performed according to Tautz and Pfeifle (1989) with modifications of the labeling and detection reaction. A detailed protocol is available upon request. Specific probes for slp1 and slp2 were obtained by amplification of carboxy-terminal fragments by the polymerase chain reaction (Saiki et al. 1985). The subcloned cDNAs were used as a template for amplification. The primers used to amplify the region from nucleotide 932 to 1255 of slp1 were 5'-CTCGCCTGGGATCCTATCGTCAGGC-3' and 5'-CTGCGCCGAATTCCAAGATTTAGC- $3^{\prime}$ and incorporated internal BamHI and EcoRI restriction sites (mismatches). The primers used to amplify the region from nucleotides 1201 to 1761 of SIp2 also incorporated internal BamHI and EcoRI restriction sites and were 5'-GCTGATAGGATCCATGTTCCCG-3' and 5'-GCTGATAGGATCCATGTTCCCG-3'.

Antibody stainings were performed essentially as described by Frasch et al. (1987). Primary and secondary antibodies were preadsorbed against embryos for $6-12 \mathrm{hr}$ at $4^{\circ} \mathrm{C}(10 \times$ final concentration). The mouse monoclonal anti- $\beta$-gal antibody was obtained from Promega Biotec. The rabbit polyclonal anti-eve (Frasch et al. 1987) and anti-ftz antibodies (Krause et al. 1988) were gifts from M. Frasch (Mount Sinai Medical Center, New York) and $\mathrm{H}$. Krause (Toronto University, Canada). The anti- $\beta$ gal, anti-eve, and anti-ftz antibodies were used at a dilution of $1: 1000,1: 2000$, and $1: 200$, respectively. The secondary biotinylated goat antimouse (Elite ABC Kit, Vectastain) and alkaline phosphatase-conjugated swine anti-rabbit antibodies $(\mathrm{Da}$ kopatts) were used at a dilution of $1: 500$ and $1: 100$. The biotinylated antibody was detected with the Elite ABC Kit and the color reaction was performed according to the protocol provided by the manufacturer. For double-labeling experiments both primary antibodies were incubated simultaneously. The alkaline phosphatase reaction was performed first and was followed by incubation with the $\mathrm{ABC}$ complex and detection of horseradish peroxidase.

\section{Acknowledgments}

We would like to thank Christiane Nüsslein-Volhard and Janos Szidonya for providing mutant fly stocks, Bill Engels for flies carrying a stable source of $\Delta 2-3$ transposase, and Manfred Frasch and Henry Krause for the gift of anti-eve and anti-ftz antibodies, respectively. Paul Baumgartner provided invaluable help with sequencing and Paul Jenö synthesized the primers used during this work. Larry Kauvar, Bernd Hoveman, and Tom Maniatis kindly provided cDNA and genomic libraries. We are grateful to Ken Cadigan for his help in sorting out the relationship between slp and other pair-rule gene expression patterns, to Shigeru Kondo for helping with Figure 3, A and C, and to Reinhard Dölz for introducing us to the secrets of working with yogi (VAX). Our thanks also go to all members of the Gehring laboratory for their support and advice, and in particular to Ken Cadigan, Alex Schier, Markus Affolter, Anette Preiss, and Angela Krämer for critical reading of the manuscript. Final thanks go to Erika Wenger-Marquardt for efficiently typing the manuscript. This work was supported by a fellowship of the Stipendienfonds der Basler Chemischen Industrie to U.G., an American Cancer Society fellowship to R.K.P., the Swiss National Science Foundation and the Kantons of Basel-Stadt and Basel-Landschaft.

The publication costs of this article were defrayed in part by payment of page charges. This article must therefore be hereby marked "advertisement" in accordance with 18 USC section 1734 solely to indicate this fact.

\section{Note added in proof}

The sequences reported in this article have been submitted to the EMBL data base.

\section{References}

Affolter, M., A. Schier, and W.J. Gehring. 1990. Homeodomain proteins and the regulation of gene expression. Curr. Opin. Cell Biol. 2: 485-495.

Akam, M. 1987. The molecular basis for metameric pattern in the Drosophila embryo. Development 101: 1-22.

Baumgartner, S., D. Bopp, M. Burri, and M. Noll. 1987. Structure of two genes at the gooseberry locus related to the paired gene and their spatial expression during Drosophila embryogenesis. Genes \& Dev. 1: 1247-1267.

Baker, N.E. 1987. Molecular cloning of wingless, a segment polarity gene in Drosophila. The spatial distribution of a transcript in embryos. EMBO /. 6: 1765-1773.

Bellen, H.J., C.J. O'Kane, C. Wilson, U. Grossniklaus, R. Kurth Pearson, and W.J. Gehring. 1989. P-element-mediated enhancer detection: A versatile method to study development in Drosophila. Genes \& Dev. 3: 1288-1300.

Bownes, M. and B.A. Hodson. 1980. Mutant $f_{s}(1) 1163$ of Drosophila melanogaster alters yolk protein secretion from fat body. Mol. Gen. Genet. 180: 411-418.

Campos-Ortega, J.A. and V. Hartenstein. 1985. The embryonic development of Drosophila melanogaster. Springer-Verlag, Berlin.

Cavener, P.R. 1987. A comparison of the consensus sequence flanking translational start sites in Drosophila and vertebrates. Nucleic Acids. Res. 15: 1353-1361.

Cohen, S.M. and G. Jürgens. 1990. Mediation of Drosophila head development by gap-like segmentation genes. Nature 346: 482-485. 
Coleman, K.G., S.J. Poole, M.P. Weir, W.C. Soeller, and T. Kornberg. 1987. The invected gene of Drosophila: Sequence analysis and expression studies reveal a close kinship to the engrailed gene. Genes \& Dev. 1: 19-28.

Côté, S., A. Preiss, J. Haller, R. Schuh, A. Kienlin, E. Seifert, and H. Jäckle. 1987. The gooseberry-zipper region of Drosophila: Five genes encode different spatially restricted transcripts in the embryo. EMBO I. 6: 2793-2801.

Coulter, D.E. and E. Wieschaus. 1988. Gene activities and segmental patterning in Drosophila, analysis of odd-skipped and pair-rule double mutants. Genes \& Dev. 2: 1812-1823.

Coulter, D.E., E.A. Swaykus, M. Beran-Koehn, D. Goldberg, E. Wieschaus, and P. Schedl. 1990. Molecular analysis of oddskipped, a zinc finger encoding segmentation gene with a novel pair-rule expression pattern. EMBO I. 8: 3795-3804.

Devereux, J., P. Haeberli, and O. Smithies. 1984. A comprehensive set of sequence analysis programs for the VAX. Nucleic Acids Res. 12: 387-395.

DiNardo, S. and P.H. O'Farrell. 1987. Establishment and refinement of segmental pattern in the Drosophila embryo: Spatial control of engrailed expression by pair-rule genes. Genes \& Dev. 1: 1212-1225.

DiNardo, S., J.M. Kuner, J. Theis, and P.H. O'Farrell. 1985. Development of embryonic pattern in $D$. melanogaster as revealed by accumulation of the nuclear engrailed protein. Cell 43: 59-69.

Doyle, H.J., R. Kraut, and M. Levine. 1989. Spatial regulation of zerknüllt: A dorsal-ventral patterning gene in Drosophila. Genes \& Dev. 3: 1518-1533.

Eldon, E.D. and V. Pirotta. 1991. Interactions of the Drosophila gap gene giant with maternal and zygotic pattern forming genes. Development 111: 367-378.

Fasano, L., L. Röder, N. Coré, E. Alexandre, C. Vola, B. Jacq, and S. Kerridge. 1991. The gene teashirt is required for the development of Drosophila embryonic trunk segments and encodes a protein with widely spaced zinc finger motifs. Cell 64: 63-79.

Finkelstein, R. and N. Perrimon. 1990. The orthodenticle gene is regulated by bicoid and torso and specifies Drosophila head development. Nature 346: 485-488.

Fjose, A., W.J. McGinnis, and W.J. Gehring. 1985. Isolation of a homeo box-containing gene from the engrailed region of Drosophila and the spatial distribution of its transcripts. $\mathrm{Na}$ ture 313: 284-289.

Forrester, W.C., S. Takegawa, T. Papayannopoulou, G. Stamatoyannopoulos, and M. Groudine. 1987. Evidence for a locus activator region. Nucleic Acids Res. 15: 10159-10177.

Frasch, M., T. Hoey, C. Rushlow, H. Doyle, and M. Levine. 1987. Characterization and localization of the even-skipped protein of Drosophila. EMBO I. 6: 749-759.

Garabedian, M.J., M.-C. Hung, and P.C. Wensink. 1985. Independent control elements that determine yolk protein gene expression in alternative Drosophila tissues. Proc. Natl. Acad. Sci. 82: 1396-1400.

Gergen, J.P. and B.A. Butler. 1988. Isolation of the Drosophila segmentation gene runt and analysis of its expression during embryogenesis. Genes \& Dev. 2: 1179-1193.

Grossniklaus, U., H.J. Bellen, C. Wilson, and W.J. Gehring. 1989. P-element-mediated enhancer detection applied to the study of oogenesis in Drosophila. Development 107: 189200.

Grosveld, F., G. Blom van Assendelft, D.R. Greaves, and G. Kollias. 1987. Position-independent high level of expression of the human $\beta$-globin gene in transgenic mice. Cell 51: 975 985.

Hafen, E., A. Kuroiwa, and W.J. Gehring. 1984. Spatial distribu- tion of transcripts from the segmentation gene fushi tarazu during Drosophila embryonic development. Cell 37: 833841 .

Hanscombe, O., D. Whyatt, P. Fraser, N. Yannoutsos, D. Greaves, N. Dillon, and F. Grosveld. 1991. Importance of globin gene order for correct developmental expression. Genes \& Dev. 5: 1387-1394.

Harding, K., H.J. Rushlow, T. Doyle, and M.S. Levine. 1986. Cross-regulatory interactions among pair-rule genes in Drosophila. Science 233: 953-959.

Hayashi, S. and M.P. Scott. 1990. What determines the specificity of action of Drosophila homeodomain proteins. Cell 63: $883-894$.

Hovemann, B., S. Richter, U. Walldorf, and C. Cziepluch. 1988. Two genes encode related cytoplasmic elongation factors $1 \alpha$ (EF-l $\alpha)$ in Drosophila melanogaster with continuous and stage specific expression. Nucleic Acids Res. 16: 3175-3194.

Hung, M. and P.C. Wensink. 1983. Sequence and structure conservation in yolk proteins and their genes. I. Mol. Biol. 164: $481-492$.

Ingham, P.W. 1988. The molecular genetics of embryonic pattern formation in Drosophila. Nature 335: 25-34.

-1991. Segment polarity genes and cell patterning within the Drosophila body segment. Curr. Opin. Genet. Dev. 1: 261-267.

Ingham, P.W., K.R. Howard, and D. Ish-Horowicz. 1985. Transcription pattern of the Drosophila segmentation gene hairy. Nature 318: 439-445.

Jürgens, G., R. Lehmann, M. Schardin, and C. Nüsslein-Volhard. 1986. Segmental organization of the head in the embryo of Drosophila melanogaster. A blastoderm fate map of the cuticle structures of the larval head. Wilh. Roux's Arch. Dev. Biol. 195: 359-377.

Kassis, J.A. 1990. Spatial and temporal control elements of the Drosophila engrailed gene. Genes \& Dev. 4: 433-443.

Kaufman, T.C., E. Lewis, and B. Wakimoto. 1980. Cytogenetic analysis of chromosome 3 in Drosophila melanogaster: The homeotic gene complex in polytene chromosome interval 84A-B. Genetics 94: 115-133.

Kilchherr, F., S. Baumgartner, D. Bopp, E. Frei, and M. Noll. 1986. Isolation of the paired gene of Drosophila and its spatial expression during early embryogenesis. Nature 321: 493-499.

Knipple, D.C., E. Seifert, U.B. Rosenberg, A. Preiss, and H. Jäckle. 1985. Spatial and temporal expression patterns of Krüppel gene expression in early Drosophila embryos. $\mathrm{Na}$ ture 317: 40-44.

Kornberg, T. 1981. Engrailed: A gene controlling compartment and segment formation in Drosophila. Proc. Natl. Acad. Sci. 78: 1095-1099.

Kornberg, T., I. Sidén, P. O'Farrell, and M. Simon. 1985. The engrailed locus of Drosophila: In situ localization of transcripts reveals compartment-specific expression. Cell 40: $45-53$.

Krause, H.M., R. Klemenz, and W.J. Gehring. 1988. Expression, modification, and localization of the fushi tarazu protein in Drosophila embryos. Genes \& Dev. 2: 1021-1036.

Kraut, R. and M. Lewine. 1991. Spatial regulation of the gap gene giant during Drosophila development. Development 111: 601-609.

Lai, E., K.R. Prezioso, E. Smith, O. Litvin, R.H. Costa, and J.E. Darnell, Jr. 1990. HNF-3A, a hepatocyte-enriched transcription factor of novel structure is regulated transcriptionally. Genes \& Dev. 4: 1427-1436.

Lai, E., V.R. Prezioso, W. Tao, W.S. Chen, and J.E. Darnell, Jr. 1991. Hepatocyte nuclear factor 3a belongs to a gene family 
in mammals that is homologous to the Drosophila homeotic gene fork head. Genes \& Dev. 5: 416-427.

Lawrence, P.A., P. Johnston, P. Macdonald, and G. Struhl. 1987. Borders of parasegments in Drosophila embryos are delimited by the fushi tarazu and even-skipped genes. Nature 328: $440-442$.

Lewis, E. 1978. A gene complex controlling segmentation in Drosophila. Nature 276: 565-570.

Lindsley, D.L. and G. Zimm. 1990. The genome of Drosophila melanogaster. Part 4: Genes L-Z, balancers, transposable elements. Drosophila Info. Serv. 68.

Macdonald, P.M., P. Ingham, and G. Struhl. 1986. Isolation, structure, and expression of even-skipped: A second pairrule gene of Drosophila containing a homeo box. Cell 47: 721-734.

Maniatis, T., R.C. Hardison, E. Lacy, J. Lauer, C. O'Connel, D. Quon, G.K. Sim, and A. Efstratiadis. 1978. The isolation of structural genes from libraries of eukaryotic DNA. Cell 15: $687-701$.

McGinnis, W., R.L. Garber, J. Wirz, A. Kuroiwa, and W.J. Gehring. 1984. A homologous protein-coding sequence in Drosophila homeotic genes and its conservation in other metazoans. Cell 37: 403-408.

Nüsslein-Volhard, C. and E. Wieschaus. 1980. Mutations affecting segment number and polarity in Drosophila. Nature 287: 795-801.

Nüsslein-Volhard, C., E. Wieschaus, and H. Kluding. 1984. Mutations affecting the pattern of the larval cuticle in Drosophila melanogaster. I. Zygotic loci on the second chromosome. Wilh. Roux's Arch. Dev. Biol. 193: 267-282.

Nüsslein-Volhard, C., H. Kluding, and G. Jürgens. 1985. Genes affecting the segmental subdivision of the Drosophila embryo. Cold Spring Harbor Symp. Quant. Biol. 50: 145-154.

Payre, F., S. Noselli, V. Lefrère, and A. Vincent. 1990. The closely related Drosophila sry $\beta$ and sry $\delta$ zinc finger proteins show differential embryonic expression and distinct patterns of binding sites on polytene chromosomes. Development 110: 141-149.

Pearson, W.R. and D.J. Lipman. 1988. Improved tools for biological sequence comparison. Proc. Natl. Acad. Sci. 85: 2444-2448.

Poole, S.J., L.M. Kauvar, B. Drees, and T. Kornberg. 1985. The engrailed locus of Drosophila: Structural analysis of an embryonic transcript. Cell 40: 37-43.

Proudfoot, N.J. and G.G. Brownlee. 1976. 3' Non-coding region sequences in eukaryotic messenger RNA. Nature 263: 211214.

Pultz, M.A., R.J. Diederich, D.L. Cribbs, and T.C. Kaufman. 1988. The proboscopedia locus of the Antennapedia complex: A molecular and genetic analysis. Genes \& Dev. 2: 901-920.

Reuter, G. and J. Szidonya. 1983. Cytogenetic analysis of variegation suppressors and a dominant temperature-sensitive lethal in region 23-26 of chromosome $2 \mathrm{~L}$ in Drosophila melanogaster. Chromosoma 88: 277-285.

Robertson, H.M., C.R. Preston, R.W. Phillis, D.M. JohnsonSchiltz, W.K. Benz, and W.R. Engels. 1988. A stable source of P-element transposase in Drosophila melanogaster. Genetics 118: 461-470.

Rosenberg, U.B., C. Schröder, A. Preiss, A. Kienlin, S. Coté, I. Riede, and H. Jäckle. 1986. Structural homology of the product of the Drosophila Krüppel gene with Xenopus transcription factor IIIA. Nature 319: 336-339.

Rushlow, C., H. Doyle, T. Hoey, and M. Levine. 1987. Molec ular characterization of the zerknüllt region of the Antennapedia gene complex in Drosophila. Genes \& Dev. 1: 1268-
1279.

Saiki, R.K., S. Scharf, F. Faloona, K.B. Mullis, G.T. Horn, H.A. Erlich, and N. Armheim. 1985. Enzymatic amplification of $\beta$-globin genomic sequences and restriction site analysis for diagnosis of sickle cell anemia. Science 230: 1350-1354.

Sambrook, I., E.F. Fritsch, and T. Maniatis. 1989. Molecular cloning: A laboratory manual. Cold Spring Harbor Laboratory Press, Cold Spring Harbor, New York.

Scott, M.P. and A.J. Weiner. 1984. Structural relationships among genes that control development: Sequence homology between the Antennapedia, Ultrabithorax and fushi tarazu loci of Drosophila. Proc. Natl. Acad. Sci. 81: 4115-4119.

Tautz, D. and C. Pfeifle. 1989. A non-radioactive in situ hybridization method for the localization of specific RNAs in Drosophila embryos reveals translational control of the segmentation gene hunchback. Chromosoma 98: 81-85.

Tautz D., R. Lehmann, H. Schnürch, R. Schuh, E. Seifert, A. Kienlin, K. Jones, and H. Jäckle, H. 1987. Finger protein of novel structure encoded by hunchback, a second member of the gap class of Drosophila segmentation genes. Nature 327: 383-389.

Tearle, R. and C. Nüsslein-Volhard. 1987. Tübingen mutants and stocklist. Drosophila Info. Serv. 66: 209-269.

Turner, F.R. and A.P. Mahowald. 1979. Scanning electron microscopy of Drosophila melanogaster embryogenesis. III. Formation of the head and caudal segments. Dev. Biol. 86: $96-109$.

Vincent, A., H.V. Colot, and M. Rosbash. 1985. Sequence and structure of the serendipity locus of Drosophila melanogaster. A densely transcribed region including a blastoderm specific gene. I. Mol. Biol. 186: 149-166.

Wakimoto, B.T., F.R. Turner, and T.C. Kaufman. 1984. Defects in embryogenesis in mutants associated with the Antennapedia gene complex of Drosophila melanogaster. Dev. Biol. 102: $147-172$.

Weigel, D. and H. Jäckle. 1990. Fork head: A new eukaryotic DNA binding motif? Cell 63: 455-456.

Weigel, D., G. Jürgens, F. Kütter, E. Seifert, and H. Jäckle. 1989. The homeotic gene fork head encodes a nuclear protein and is expressed in the terminal regions of the Drosophila embryo. Cell 57: 645-658.

Wiliams, J.L, R.D.C. Saunders, M. Bownes, and A. Scott. 1987. Identification of a female-sterile mutation affecting yolk protein 2 in Drosophila melanogaster. Mol. Gen. Genet. 209: 360-365.

Wilson, C., R. Kurth Pearson, H.J. Bellen, C.J. O'Kane, U. Grossniklaus, and W.J. Gehring. 1989. P-element-mediated enhancer detection: An efficient method for isolating and characterizing developmentally regulated genes in Drosophila. Genes \& Dev. 3: 1301-1313. 


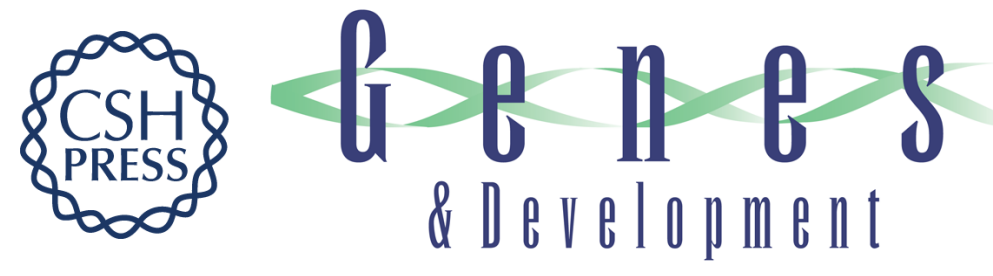

\section{The Drosophila sloppy paired locus encodes two proteins involved in segmentation that show homology to mammalian transcription factors.}

U Grossniklaus, R K Pearson and W J Gehring

Genes Dev. 1992, 6:

Access the most recent version at doi:10.1101/gad.6.6.1030

References This article cites 75 articles, 27 of which can be accessed free at: http://genesdev.cshlp.org/content/6/6/1030.full.html\#ref-list-1

License

Email Alerting Receive free email alerts when new articles cite this article - sign up in the box at the top Service right corner of the article or click here.

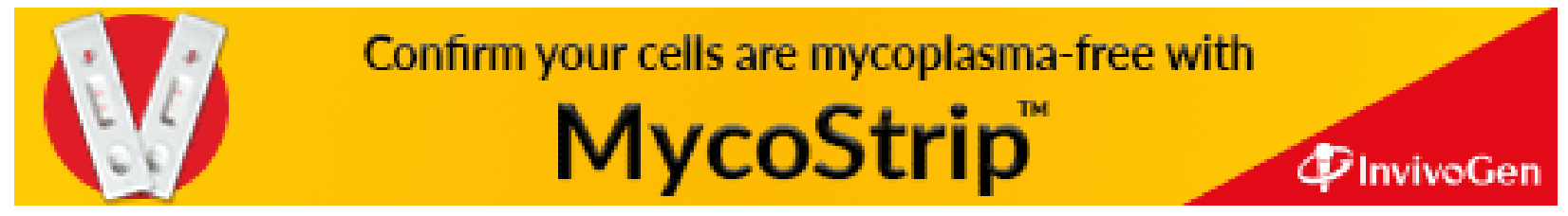

